\title{
Long-Duration Freezing Rain Events over North America: Regional Climatology and Thermodynamic Evolution
}

\author{
Christopher D. MCCRAy, Eyad H. ATAllah, AND JOHn R. GyAKum \\ Department of Atmospheric and Oceanic Sciences, McGill University, Montreal, Quebec, Canada
}

(Manuscript received 8 September 2018, in final form 19 March 2019)

\begin{abstract}
Freezing rain can cause severe impacts, particularly when it persists for many hours. In this paper, we present the climatology of long-duration (6 or more hours) freezing rain events in the United States and Canada from 1979 to 2016 . We identify three focus regions from this climatology and examine the archetypal thermodynamic evolution of events in each region using surface and radiosonde observations. Long-duration events occur most frequently in the northeastern United States and southeastern Canada, where freezing rain typically begins as lower-tropospheric warm-air advection develops the warm layer aloft. This warm-air advection and the latent heat of fusion released when rain freezes at the surface erode the cold layer, and freezing rain transitions to rain once the surface temperature reaches $0^{\circ} \mathrm{C}$. In the southeastern United States, a larger percentage of events are of long duration than elsewhere in North America. Weak surface cold-air advection and evaporative cooling in the particularly dry onset cold layers there prevent surface temperatures from rising substantially during events. Finally, the south-central United States has a regional maximum in the occurrence of the top $1 \%$ of events by duration (18 or more hours), despite the relative rarity of freezing rain there. These events are associated with particularly warm/deep onset warm layers, with persistent low-level cold-air advection maintaining the cold layer. The thermodynamic evolutions we have identified highlight characteristics that are key to supporting persistent freezing rain in each region and may warrant particular attention from forecasters tasked with predicting these events.
\end{abstract}

\section{Introduction}

Freezing rain is among the most impactful winter weather hazards, responsible for over $\$ 16$ billion in insured property losses in the United States from 1949 to 2000 (in year 2000 U.S. dollars; Changnon 2003). In Canada, the devastating 5-9 January 1998 ice storm produced more than $100 \mathrm{~mm}$ of ice accretion at some locations in southern Quebec. This resulted in longlasting power outages and caused nearly $\$ 3$ billion of damage in Canada and $\$ 1.4$ billion in adjacent parts of New England (both in 1998 U.S. dollars; Lott et al. 1998; DeGaetano 2000; Gyakum and Roebber 2001; Roebber and Gyakum 2003).

The classical formation mechanism for freezing rain is the melting process, in which snow melts completely into rain as it falls through a warm $\left(>0^{\circ} \mathrm{C}\right)$ layer aloft, with the resultant raindrops subsequently falling into a near-surface cold $\left(\leq 0^{\circ} \mathrm{C}\right)$ layer (e.g., Brooks 1920;

Corresponding author: Christopher D. McCray, christopher.mccray@ mail.mcgill.ca
Meisinger 1920; Forbes et al. 1987). The lack of remnant ice particles in the raindrop to serve as ice nuclei prevents refreezing in this layer, and freezing only occurs when the raindrops strike cold objects at the surface.

Freezing rain can also form when the cloud layer is entirely $<0^{\circ} \mathrm{C}$, via the supercooled warm rain process (Bocchieri 1980; Huffman and Norman 1988; Rauber et al. 2000). These cases are associated with upward motion within a shallow saturated layer near the surface that is too warm $\left(\geq-10^{\circ} \mathrm{C}\right)$ for most ice nuclei to be active, and precipitation forms through collision and coalescence. This typically produces smaller drops, often resulting in freezing drizzle rather than freezing rain. While still hazardous, freezing drizzle tends to cause less-extreme impacts and is also often associated with different synoptic-dynamic patterns than freezing rain (Bernstein 2000). Therefore, we focus here specifically on freezing rain, most commonly formed via the melting process.

Freezing rain is a particularly difficult forecast challenge (e.g., Ralph et al. 2005), as the melting process 
requires the maintenance of the aforementioned temperature stratification. Ice pellets form under similar atmospheric temperature/moisture profiles as freezing rain, typically with a colder/shallower warm layer aloft resulting in incomplete melting of the snowflakes (e.g., Zerr 1997). These similarities mean even slight errors in numerical weather prediction (NWP) models result in precipitation-type errors. Furthermore, many precipitation-type forecasts are generated using algorithms based on characteristics such as the depth and temperature of the warm and cold layers (e.g., Ramer 1993; Baldwin et al. 1994; Bourgouin 2000). These algorithms have great difficulty distinguishing freezing rain from ice pellets, and none of the five algorithms Reeves et al. (2014) tested accurately identified $>50 \%$ of observed soundings of both precipitation types.

More recent NWP models with bulk microphysics schemes explicitly predict hydrometeor phase using vertical profiles of the various hydrometeor mixing ratios at each grid point. For example, the High-Resolution Rapid Refresh (HRRR) model postprocesses the microphysics scheme precipitation-type output to generate a final forecast (Benjamin et al. 2016). These explicit techniques improve on the physical shortcomings of the aforementioned implicit algorithms. However, precipitation phase forecasts generated with them remain susceptible to small errors in the model temperature and moisture fields, as temperature profile differences of just $0.5^{\circ} \mathrm{C}$ affect the precipitation type reaching the surface (Thériault et al. 2010). Consequently, Ikeda et al. (2017) found that HRRR precipitation-type forecast errors were largely caused by surface temperature biases. Thus, even as NWP models become more complex and accurate in their microphysics representation, forecasters can benefit from enhanced understanding of the conditions that lead to severe freezing rain events.

The effects of diabatic processes that can erode or maintain the warm and cold layers also pose a challenge to forecasters. Stewart (1985) described freezing rain as a self-limiting process. When snowflakes melt aloft, the extraction of latent heat of fusion cools the air and can completely erode the warm layer after several hours (e.g., Wexler et al. 1954; Kain et al. 2000). Conversely, when rain freezes at the surface, the release of latent heat of fusion can warm the air to $0^{\circ} \mathrm{C}$ and transition freezing rain to rain. Lackmann et al. (2002) estimated that the release of latent heat of fusion during a freezing rain event in the Carolinas resulted in surface warming of $\approx 3^{\circ} \mathrm{C}$ over several hours. This warming from the release of latent heat of fusion can be offset via evaporative cooling in situations where the near-surface air is dry. Particularly in cases where temperature advection is weak, these diabatic effects can be important.
Because freezing rain is typically light $[\leq 2.54 \mathrm{~mm}$ ( $0.10 \mathrm{in}.) \mathrm{h}^{-1}$ ], event severity is closely related to event duration (Cortinas 2000; Ressler et al. 2012). Therefore, forecasters attempting to predict the severity of a freezing rain event must determine whether the freezing rain will persist for many hours, transition to another precipitation type, or simply cease. For events to persist for many hours, compensatory mechanisms must be in place to offset the self-limiting diabatic effects. The purpose of this paper is to identify where in North America long-duration freezing rain events (defined in section 2) occur most frequently and to explain the thermodynamic conditions supporting the persistence of these events in those regions.

\section{Data and methods}

\section{a. Surface observations}

We analyze surface observations of freezing rain from 1979-2016 for stations within the United States and Canada from NOAA's Integrated Surface Database (Smith et al. 2011). Many previously manual stations in Canada and the United States (NOAA 1998) have been automated during this period. Reeves (2016) noted that human-augmented and nonaugmented ASOS are generally consistent in their frequencies of freezing rain observations, lending confidence to the inclusion of these automated stations here. Some stations only have short periods of record, while others with human observers often did not report overnight, when freezing rain occurs most frequently (Cortinas et al. 2004). To exclude these stations, Cortinas et al. (2004) only examined sites that had reports for at least $80 \%$ of the annual hours for at least 10 of the 15 years they studied. We use the same $80 \%$ threshold, but require stations to meet this criteria for at least 30 of the 38 years in our period of study, yielding 579 stations for analysis.

\section{b. Event identification}

The severity of a freezing rain event is primarily dependent on the total ice accretion during the event, with damage sometimes compounded by high winds during or after freezing rain (e.g., Changnon 2003). An ideal dataset to identify and assess the severity of freezing rain events would contain widespread, consistent observations of ice accretion. While ice accretion is now reported by Automated Surface Observing System (ASOS) stations in the United States (Ryerson and Ramsay 2007), routine reports only became operational starting in 2013, and no similar dataset exists for Canada. Past studies that have examined conditions leading to ice storms have identified severe events using NOAA's 
Storm Data (Rauber et al. 2001; Castellano 2012; Sanders et al. 2013; Mullens et al. 2016b), which suffers from spatial and temporal inconsistencies (Branick 1997) and is only available for the United States.

Several studies have noted the importance of event duration in determining total ice accretion and event severity. For example, Ressler et al. (2012) found that $98 \%$ of freezing rain observations in their study were light and thus total event precipitation was largely dependent on duration. Cortinas (2000) and Ressler et al. (2012) used a 6-h threshold to identify long-duration events. Sanders et al. (2013) identified ice storms with at least $6.35 \mathrm{~mm}(0.25 \mathrm{in}$.) of ice accretion in the central United States using several event archives including Storm Data, and found that these storms all had a duration $\geq 9 \mathrm{~h}$. While other factors such as wind and skin temperature can impact event severity (e.g., Sanders and Barjenbruch 2016), event duration is an objective statistic calculable for all stations in both the United States and Canada over a long period of record. Therefore, we examine event duration as a proxy for event severity.

Several methods for calculating event duration have been used in prior studies, from counting only consecutive hours of freezing rain (Cortinas 2000) to allowing several intervening hours of nonfreezing rain observations (Ressler et al. 2012). Cortinas (2000) found that freezing rain tends to be near-continuous, and the precise threshold for intervening nonfreezing rain hours has little impact on event identification. Here, we count consecutive hours of freezing rain (including mixes with other precipitation types) and combine events separated by $<24 \mathrm{~h}$ at each station, such that most cases associated with the same synoptic-dynamic pattern are not separated. Tests using varying intervals resulted in roughly the same distribution of event duration.

The event onset is defined as the hour of the first freezing rain observation in an event, with the event end being the hour of the final freezing rain observation within the event. The event duration is the number of hourly observations in which freezing rain was observed. We follow Cortinas (2000) and Ressler et al. (2012) and define long-duration (LD) events as those in which six or more hours of freezing rain occurred, which account for $20 \%$ of events in the dataset. While this threshold is subjective, it allows us to identify a category of events likely causing the greatest impacts while still being sufficiently common to provide a substantial dataset to analyze.

\section{c. Radiosonde data}

We analyze atmospheric profiles of temperature and moisture using radiosonde data from the University of Wyoming archive (available online at http:// weather.uwyo.edu/upperair/sounding.html) for soundings taken at freezing rain event onset and end, provided that 1) the sounding site is located within $40 \mathrm{~km}$ of at least one of the surface stations in our dataset and 2) the sounding site and its associated surface station are separated by $<100 \mathrm{~m}$ of elevation. Radiosondes are typically released $30-60 \mathrm{~min}$ prior to the synoptic time (0000, 1200 , and occasionally 0600 or 1800 UTC). We retain any sounding available for events that began within one hour of $0500,1100,1700$, or 2300 UTC or ended within one hour of $0000,0600,1200$, or 1800 UTC. For example, a 1200 UTC sounding is retained for an event that begins between 1000 and 1200 UTC or ends between 1100 and 1300 UTC. These time ranges ensure a sufficiently large sample of profiles for both onset and end while capturing periods during which freezing rain was likely falling.

We calculate several common parameters to describe relevant characteristics of each sounding, with particular focus on the depth and maximum temperature $T_{\max }$ of the warm layer and the depth and minimum temperature $T_{\min }$ of the cold layer. We define the warm layer as the layer aloft throughout which $T>0^{\circ} \mathrm{C}$. The top of the layer is the uppermost level at which $T>0^{\circ} \mathrm{C}$, while the base is the first level below this at which $T \leq$ $0^{\circ} \mathrm{C}$. The cold layer is the near-surface layer throughout which $T \leq 0^{\circ} \mathrm{C}$. The top of the cold layer is the base of the warm layer, while the base of the cold layer is either the surface (if the surface temperature is $\leq 0^{\circ} \mathrm{C}$ ) or the first level at which the temperature falls to $0^{\circ} \mathrm{C}$ between the surface and the base of the warm layer. We also analyze moisture characteristics of the soundings by identifying a cloud layer as in Rauber et al. (2000) as one in which the dewpoint depression $T_{\mathrm{DD}}$ is $<3^{\circ} \mathrm{C}$. The cloud top is identified as the first level above this layer provided that $T_{\mathrm{DD}}>3^{\circ} \mathrm{C}$ for at least $1 \mathrm{~km}$ above the cloud top.

Temporal and spatial variability inherent to radiosonde observations (e.g., uncertainty in the radiosonde release time, radiosonde and surface stations that are not always collocated, etc.) make it difficult to ascertain whether freezing rain was actually occurring when and where the radiosonde was sampling. For example, for an event that began at 1200 UTC, the radiosonde may have sampled the environment just prior to freezing rain onset. One result of these uncertainties is that no warm layer is present in $16 \%(18 \%)$ of LD onset (end) soundings, and while some of these may be freezing rain formed via warm rain processes, visual inspection revealed that most of them have inversion layers aloft but $T_{\max }<0^{\circ} \mathrm{C}$.

Because we cannot calculate warm and cold layer characteristics for soundings without a warm layer, we identify two complementary parameters: the minimum 
temperature in the layer from 0 to $1000 \mathrm{~m}$ above ground level (AGL) $\left(T_{\min }^{0-1000 m}\right)$ and the maximum temperature in the layer from 250 to $2500 \mathrm{~m}$ AGL $\left(T_{\max }^{250-2500 \mathrm{~m}}\right)$. In $\approx 98 \%$ of soundings with a warm layer, the $T_{\text {min }}$ in the cold layer and $T_{\max }$ in the warm layer fall within these respective altitude ranges. These parameters therefore allow us to examine the portions of the sounding where we would expect the warm and cold layers to be located, regardless of the presence of a warm layer with $T_{\max }>0^{\circ} \mathrm{C}$.

\section{d. Reanalysis data}

We examine temperature and moisture advection during freezing rain events using the National Centers for Environmental Prediction (NCEP) Climate Forecast System Reanalysis (CFSR), a global reanalysis with 37 vertical levels and a horizontal grid spacing of $0.5^{\circ} \times 0.5^{\circ}$ (Saha et al. 2010). We calculate temperature advection $(-\mathbf{v} \cdot \nabla T)$ and water vapor mixing ratio advection $(-\mathbf{v} \cdot \nabla w)$ in CFSR at the surface using 2-m temperatures/ mixing ratios and $10-\mathrm{m}$ winds. We also calculate advection in the warm layer, using the altitude of warm layer $T_{\max }$ and the level of $T_{\max }^{250-2500 \mathrm{~m}}$. Calculations at these two levels produce the same qualitative results, so we discuss only the results at the level of $T_{\max }^{250-2500 \mathrm{~m}}$ here.

We expect some error in the CFSR calculations, particularly for surface advection in the vicinity of complex terrain. To avoid the largest erroneous values, we perform advection calculations only for locations and event onset and end times for which we have observed soundings, as these sounding data are assimilated in the CFSR. We apply a weak Gaussian smoother to the calculated advection fields using the MetPy (May et al. 2017) smooth_gaussian function (with $n=3$ ) to avoid sampling highly localized extrema. We then retrieve the value at the nearest grid point to the surface station. As expected, the magnitudes of the smoothed values are slightly lower than the unsmoothed values, and both produce the same qualitative results.

\section{Regional climatology of long-duration freezing rain}

\section{a. Climatology of long-duration freezing rain events}

The climatology of freezing rain has been presented in several studies for particular U.S. regions (Gay and Davis 1993; Cortinas 2000; Castellano 2012), the United States overall (Rauber et al. 2001; Robbins and Cortinas 2002; Changnon 2003), Canada (McKay and Thompson 1969; Stuart and Isaac 1999), and North America (Cortinas et al. 2004). In our dataset, the climatology of annual freezing rain hours (Fig. 1a) during the 1979-2016 period compares well with that of Cortinas et al. (2004) for 1976-1990 (see their Fig. 2). Freezing rain occurs most frequently over southeastern Canada and the northeastern United States, where many stations observe a median of $\geq 20 \mathrm{~h} \mathrm{yr}^{-1}$ of freezing rain. The region of $\geq 10 \mathrm{~h} \mathrm{yr}^{-1}$ extends southwestward to Oklahoma and southward to the Carolinas east of the Appalachians. Only four stations observe a median of $\geq 40 \mathrm{~h} \mathrm{yr}^{-1}$ of freezing rain: St. John's (CYYT) and Gander (CYQX), Newfoundland (56 and $50.5 \mathrm{~h} \mathrm{yr}^{-1}$, respectively), Mirabel, Quebec (CYMX, $45 \mathrm{~h} \mathrm{yr}^{-1}$ ) and Ottawa, Ontario (CYOW, $\left.41.5 \mathrm{~h} \mathrm{yr}^{-1}\right)$.

The climatology of LD events (Fig. 1b) largely mirrors that of freezing rain hours. Most stations in North America observe fewer than one LD event every two years. The region with several stations observing at least $1 \mathrm{LD}$ event $\mathrm{yr}^{-1}$ stretches from Oklahoma to Newfoundland and southward to North Carolina. Five stations observe the maximum median of $3 \mathrm{LD}$ events $\mathrm{yr}^{-1}$ : CYQX and CYYT, in the eastern Newfoundland maximum in annual freezing rain hours, and CYMX, CYOW, and Bagotville, Quebec (CYBG) in the St. Lawrence River Valley, where freezing rain is maintained via low-level cold-air advection resulting from pressure-driven wind channeling (Whiteman and Doran 1993; Roebber and Gyakum 2003; Carrera et al. 2009; Razy et al. 2012; Ressler et al. 2012).

Overall, LD events account for only $20 \%$ of all cases. In some locations, however, LD events are more common than shorter-duration ones (Fig. 1c). This is true for much of the Carolinas and Georgia where freezing rain is typically associated with Appalachian cold-air damming (CAD; e.g., Richwien 1980; Forbes et al. 1987; Bell and Bosart 1988). For example, $37 \%$ of recorded events at CYOW were LD, but at Greensboro, North Carolina (KGSO), LD events account for $52 \%$ of all cases. While freezing rain occurs less frequently in this region than areas farther north, when freezing rain does occur here, it tends to more frequently persist for at least $6 \mathrm{~h}$.

Finally, the climatology of events of duration $\geq 18 \mathrm{~h}$ (the 99th percentile of duration) is displayed in Fig. 1d. Though the rarity of these events results in large spatial variability in these counts, several regional patterns appear. First, the two maximum values occur in the complex terrain of the Pacific Northwest, with Terrace, British Columbia (CYXT) and Portland, Oregon (KPDX) having observed 11 and 10 of these events, respectively. Many stations in eastern North America have also observed several of these cases, with a regional maximum at Sydney, Nova Scotia (CYQY, 8 events). One particularly striking pattern in Fig. 1d is over the south-central United States. Six stations in Kansas, Oklahoma, Texas, and Missouri have observed $\geq 6$ of these events, including 
Median annual freezing rain hours

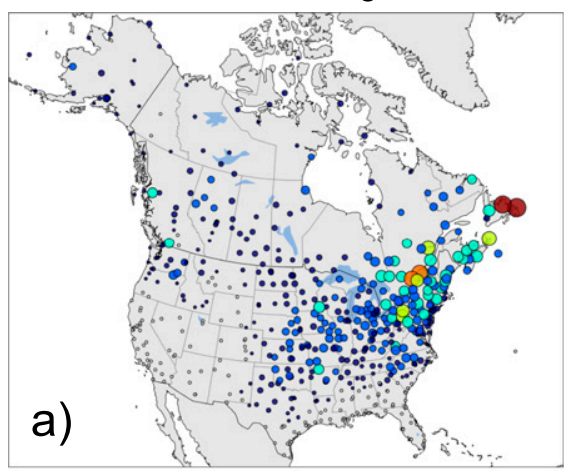

Percentage of events that are LD

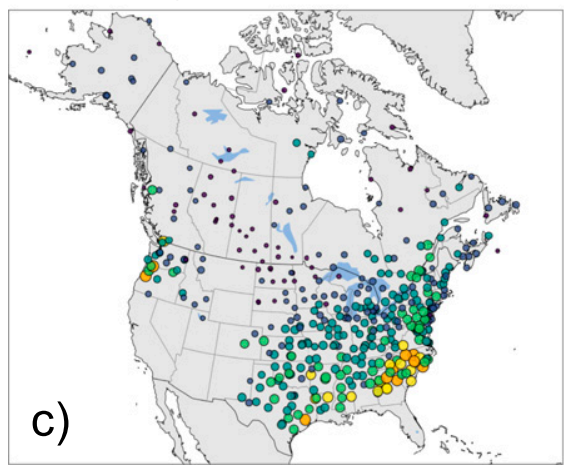

Median annual LD freezing rain events

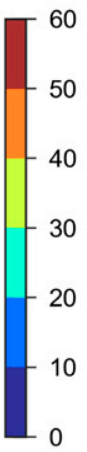

b)

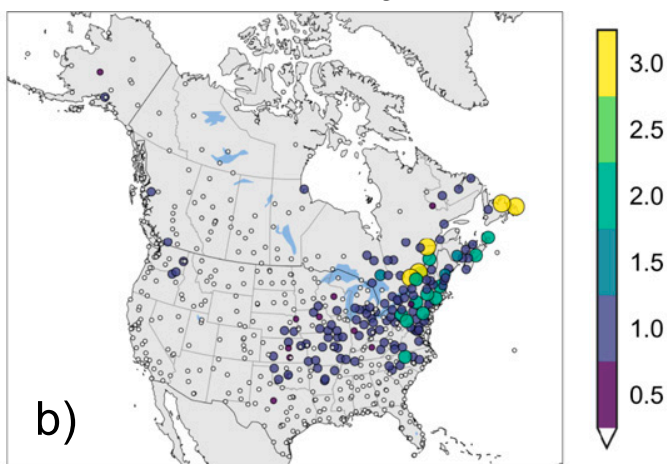

Number of events $\geq 18 \mathrm{~h}$

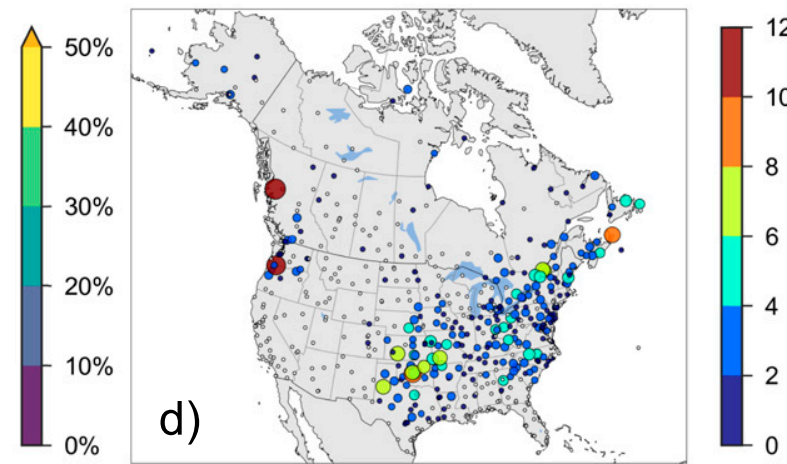

FIG. 1. Climatology of freezing rain and LD events from 1979-2016: (a) median annual hours of freezing rain at each station, (b) median annual LD freezing rain events at each station, (c) percentage of freezing rain events at each station that are LD (only stations having observed at least five LD events are plotted), and (d) number of freezing rain events of at least $18 \mathrm{~h}$ duration observed at each station. Point sizes are scaled to the value of the field plotted.

Oklahoma City, Oklahoma (KOKC, 9 events), in a region where many stations observe $<10 \mathrm{~h} \mathrm{yr}^{-1}$ of freezing rain (Fig. 1a).

\section{b. Regional aggregation}

This climatology highlights several notable regional patterns. Past studies using observed soundings during freezing rain events (e.g., Zerr 1997; Robbins and Cortinas 2002) have relied on datasets with small sample sizes, as freezing rain occurs infrequently relative to snow or rain (e.g., Cortinas et al. 2004) and upper-air observations are typically only made twice daily. Our focus on LD events limits the potential sample even further, since most stations observe fewer than $1 \mathrm{LD}$ event $\mathrm{yr}^{-1}$ (Fig. 1b). To mitigate these issues, we group stations into three focus regions (Fig. 2) based upon the aforementioned climatology, and aggregate observations at surface and upper-air stations within these regions:

- The south-central United States (SCUS) group outlines the region of disproportionately frequent $18+\mathrm{h}$ events relative to annual freezing rain hours (Fig. 1d).
- The northeastern United States/southeastern Canada (NEUS/SECA) group covers most stations east of the SCUS group that observe $\geq 20 \mathrm{~h} \mathrm{yr}^{-1}$ of freezing rain (Fig. 1a) and $\geq 1 \mathrm{LD}^{\mathrm{avent}} \mathrm{yr}^{-1}$ (Fig. 1b).

- The southeastern United States (SEUS) group consists of stations in the southward protrusion of the median $\geq 1$ LD events $\mathrm{yr}^{-1}$ east of the Appalachians (Fig. 1b), and where a majority of events are LD at many stations (Fig. 1c).

These regional differences are evidenced when examining the distributions of event duration in each region (Fig. 3). In the NEUS/SECA, the distribution is dominated by shorter-duration events, with $57 \%$ lasting $\leq 3 \mathrm{~h}$. The distribution is broader in the SEUS, where only $46 \%$ of events are $\leq 3 \mathrm{~h}$, while $33 \%$ fall in the $\geq 6$ - and $<18$-h range, compared with $23 \%$ in the NEUS/SECA and $24 \%$ in the SCUS. In the SCUS, a relatively large percentage of events are $\geq 18 \mathrm{~h}$ (3.1\%), compared with $2.1 \%$ and $0.9 \%$ for the SEUS and NEUS/SECA, respectively, while $56 \%$ of events are $\leq 3 \mathrm{~h}$. 


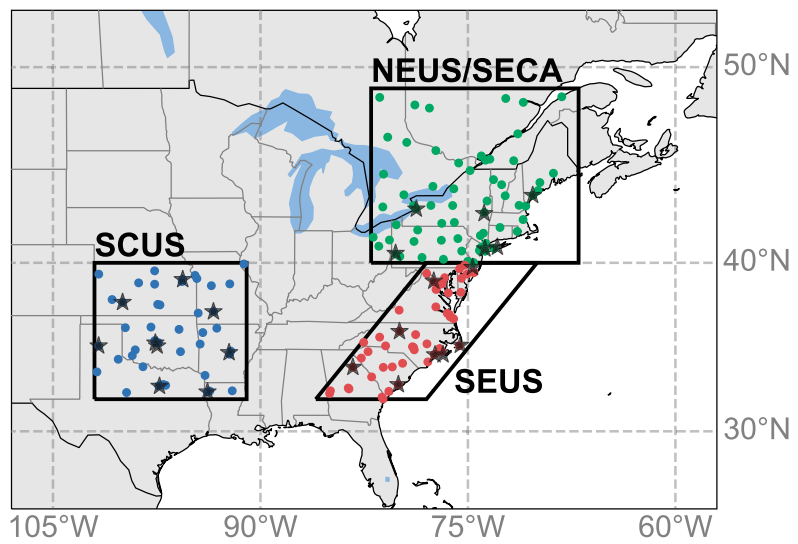

FIG. 2. Focus regions used to aggregate surface stations (dots) and upper-air stations (stars). Regions are chosen based on the climatology discussed in the text, and include the northeastern United States/southeastern Canada (NEUS/SECA), the south-central United States (SCUS), and the southeastern United States (SEUS).

We restrict most of our analysis to these three regions, as they exhibit spatially coherent climatological characteristics. These focus regions also contain relatively large populations $-\approx 20$ million for the SCUS, $\approx 30$ million for the SEUS, and $\approx 75$ million for the NEUS/ SECA - and thus a freezing rain event in each has a large potential societal and economic impact. Two notable omissions are Atlantic Canada, including eastern Newfoundland, where the largest median values of annual freezing rain hours are found (Fig. 1a), and the Pacific Northwest, where several stations observe $\geq 1 \mathrm{LD}$ event $\mathrm{yr}^{-1}$ (Fig. 1b). Both regions exhibit large spatial variability in the climatology due to complex terrain and proximity to the ocean. These regions merit further analysis in a future study.

\section{Regional thermodynamic evolution of long-duration freezing rain events}

We now examine the evolution of thermodynamic conditions during LD freezing rain events in each of our three focus regions. We analyze surface observations of temperature and $T_{\mathrm{DD}}$ at event onset and end, as well as the precipitation phase in the one hour preceding event onset and following event end. We limit statistical analysis of phase changes to observations prior to 1995 , roughly the preautomation period, as automated stations are unable to detect ice pellets or freezing drizzle (NOAA 1998).

We also compare our regionally aggregated radiosonde observations taken at LD event onset with those taken at LD event end to understand the typical thermodynamic evolution of these events aloft. We interpolate all soundings to height AGL in 1-m increments, allowing us to composite soundings taken at stations within a given region regardless of their surface elevation. We then examine

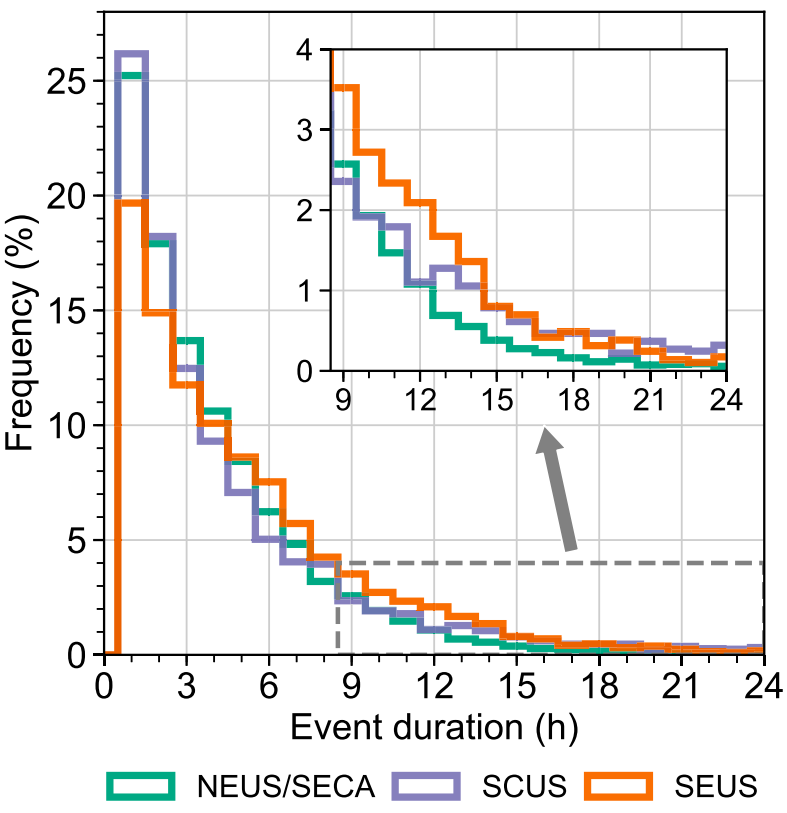

FIG. 3. Relative frequencies (\%) of event duration among all freezing rain events at stations in the NEUS/SECA (green), SCUS (purple), and SEUS (orange). The inset magnifies the histogram for events $\geq 8 \mathrm{~h}$ for comparison between regions.

sounding characteristics and advection calculations in each region. We determine statistically significant differences between thermodynamic characteristics at event onset and end using a two-tailed Student's $t$ test (Wilks 2011), with significant differences reported for $p<0.01$.

\section{a. Northeastern United States/southeastern Canada}

At LD event onset, the NEUS/SECA observes the shallowest, coolest warm layers of the three regions, with a median depth of $711 \mathrm{~m}, T_{\max }$ of $1.8^{\circ} \mathrm{C}$ (Figs. $4 \mathrm{~d}$,e), and a warm layer absent altogether from $19 \%$ of soundings. The median $T_{\max }^{250-2500 \mathrm{~m}}$ among the soundings lacking a warm layer is $-0.5^{\circ} \mathrm{C}$, suggesting the radiosonde either sampled the environment just prior to warm layer development, or freezing rain was occurring at the surface station but not at the upper-air site. The combination of soundings without a warm layer and those with weak warm layers at varying altitudes (the NEUS/SECA has the largest standard deviation of the height of warm layer $T_{\max }(540 \mathrm{~m})$ of the three regions) results in a smeared warm layer in the composite sounding ${ }^{1}$ (Fig. 5a).

\footnotetext{
${ }^{1}$ The composite soundings in Fig. 5 represent the median/spread of temperatures at individual levels AGL. As the median temperature at NEUS/SECA onset is $<0^{\circ} \mathrm{C}$ at all levels AGL, a $>0^{\circ} \mathrm{C}$ warm layer does not appear in the composite. The reader should refer to Fig. 5 for the qualitative sounding structure and evolution, but to Fig. 4 for quantitative statistics of warm/cold layer characteristics.
} 
a) Cold layer depth (m)

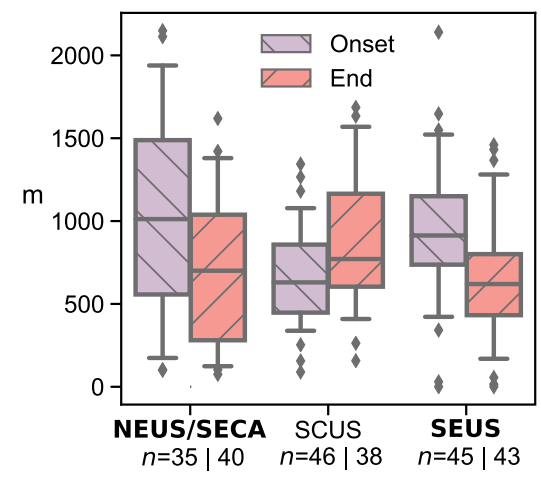

d) Warm layer depth $(\mathrm{m})$

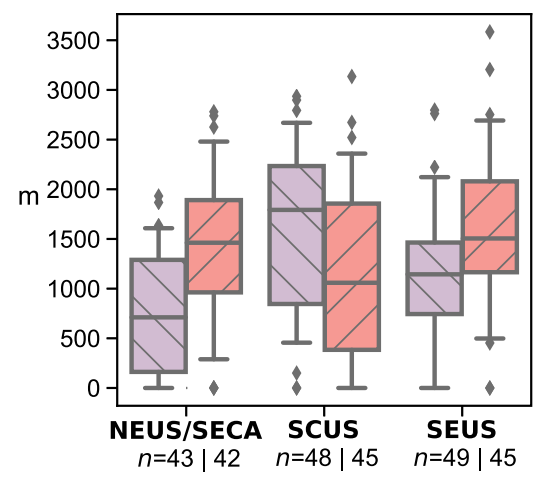

b) Cold layer $\mathrm{T}_{\min }\left({ }^{\circ} \mathrm{C}\right)$

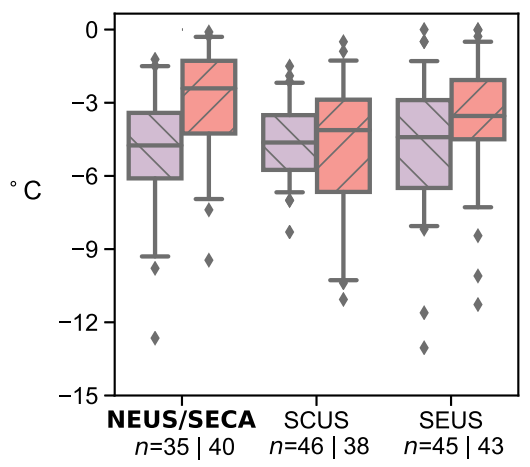

e) Warm layer $T_{\max }\left({ }^{\circ} \mathrm{C}\right)$

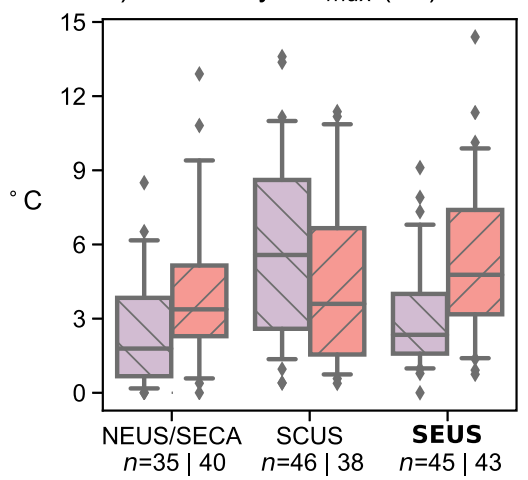

c) $T_{\min } 0-1000 \mathrm{~m} \mathrm{AGL}\left({ }^{\circ} \mathrm{C}\right)$

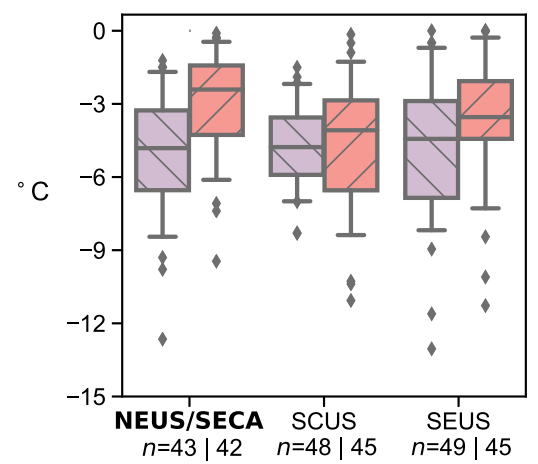

f) $T_{\max } 250-2500 \mathrm{~m} \mathrm{AGL}\left({ }^{\circ} \mathrm{C}\right)$

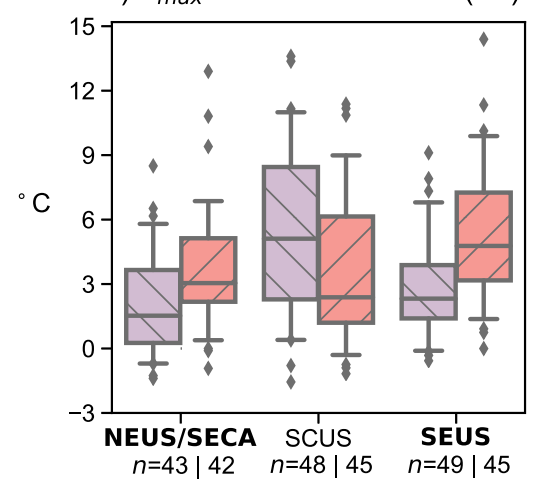

FIG. 4. Boxplots of cold layer (a) depth and (b) minimum temperature, (c) the minimum temperature in the 0-1000 m AGL layer, warm layer (d) depth and (e) maximum temperature, and (f) the maximum temperature in the 250-2500 $\mathrm{m}$ AGL layer at LD event onset (purple) and LD event end (orange) in each focus region discussed in the text. Sample sizes are listed under each region (in the format $\left.n_{\text {onset }} \mid n_{\text {end }}\right)$. Bold region names indicate that the onset and end distributions are statistically significantly different for $p<0.01$. The interquartile range is shaded, with the median indicated by the horizontal line, and whiskers stretching below to the 5 th percentile and above to the 95 th percentile. Outliers beyond these ranges are plotted as diamonds.

At the surface, the NEUS/SECA observes relatively cold onset temperatures compared with regions to the south, with a regional mean (median) of $-3.0^{\circ} \mathrm{C}$ $\left(-2.7^{\circ} \mathrm{C}\right)$ (Fig. 6a). The median onset cold layer is also the deepest and coldest of the three regions, with a median depth of $1012 \mathrm{~m}$ and $T_{\min }$ of $-4.8^{\circ} \mathrm{C}$ (Figs. 4a,b).

Precursor conditions to LD event onset in the NEUS/ SECA are thus generally cold, and $51 \%$ of events are immediately preceded by frozen precipitation (snow/ice pellets) (Table 1). The first freezing rain observation during $45 \%$ of LD events contains a mix with snow or ice pellets. Stewart and King (1987) found that snowflakes only partially melt when falling through warm layers for which $0.8^{\circ} \mathrm{C} \lesssim T_{\max } \lesssim 3.8^{\circ} \mathrm{C}$, and the observed values of $T_{\max }^{250-2500 \mathrm{~m}}$ in the NEUS/SECA fall largely within this range (Fig. 4f).

The median wind profile at LD onset shows substantial veering from just above the surface to the top of the warm layer (Fig. 5a), indicative of strong warm-air advection (WAA) through this layer. Median temperature advection at the level of $T_{\max }^{250-2500 \mathrm{~m}}$ at onset is $+3.0^{\circ} \mathrm{C}(3 \mathrm{~h})^{-1}$ (Fig. 7b). Weak median WAA $\left[+0.1^{\circ} \mathrm{C}(3 \mathrm{~h})^{-1}\right]$ is also calculated at the surface (Fig. 7a), though $42 \%$ of cases have surface cold-air advection (CAA) $\left[-\mathbf{v} \cdot \nabla T<0^{\circ} \mathrm{C}(3 \mathrm{~h})^{-1}\right]$, consistent with the northerly component to the surface winds in the composite sounding (Fig. 5a).

The strong WAA aloft warms the warm layer and erodes the cold layer from above during events (Fig. 5a). By LD event end, the median warm layer more than doubles in depth to $1462 \mathrm{~m}$ and $T_{\max }$ rises $1.6^{\circ} \mathrm{C}$, while the median cold layer erodes to a depth of $700 \mathrm{~m}$ and $T_{\min }$ increases to $-2.4^{\circ} \mathrm{C}$ (Fig. 4). Surface warming is especially strong during LD events at NEUS/SECA stations compared with the other regions studied. Surface temperatures rise during $78 \%$ of events, with a regional mean (median) increase of $+2.2^{\circ} \mathrm{C}\left(+2.0^{\circ} \mathrm{C}\right)$ from event onset to end (Fig. 6c).

Surface temperatures are $\geq 0{ }^{\circ} \mathrm{C}$ by the end of $52 \%$ of events, and freezing rain therefore transitions to liquid precipitation (rain/drizzle) after $43 \%$ of events (Table 1 ). Median WAA at the level of $T_{\max }^{250-2500 \mathrm{~m}}$ decreases by event 
a) NEUS/SECA

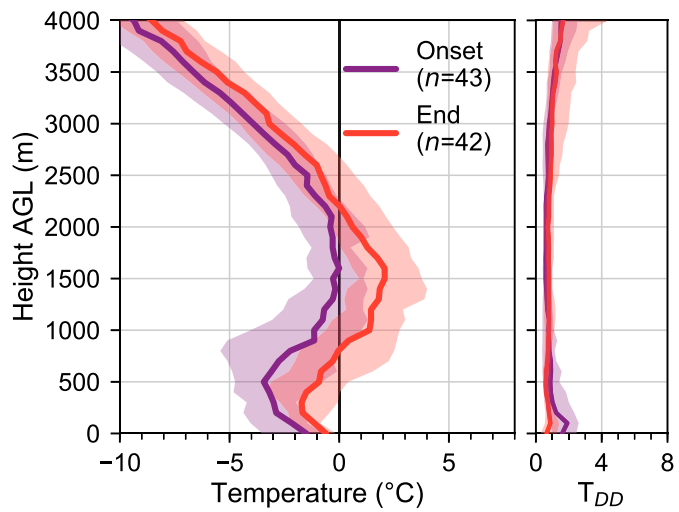

b) SCUS

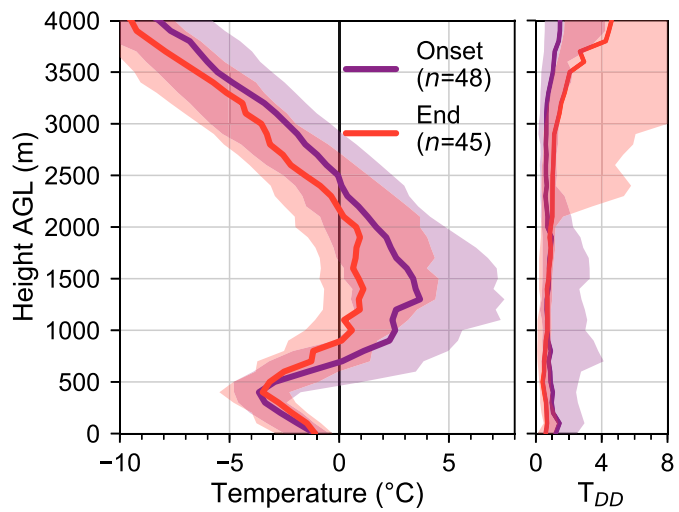

c) SEUS

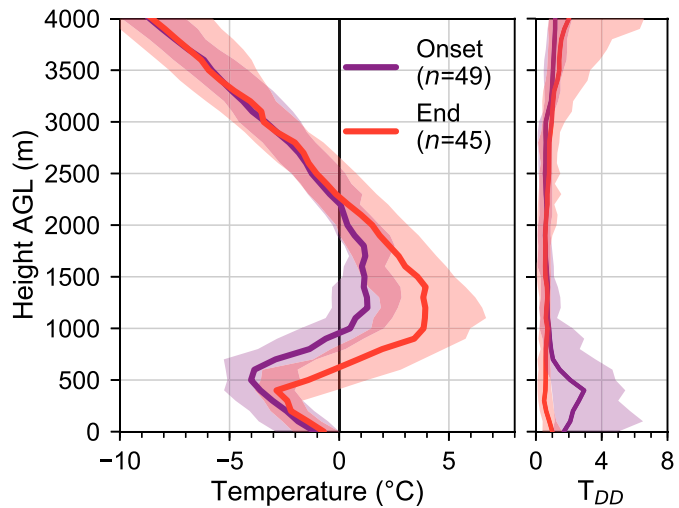

FIG. 5. Regionally composited observed soundings displaying (left) median temperature profiles (solid lines) and the interquartile range of temperature (shaded), (center) the median dewpoint depression $T_{\mathrm{DD}}$ profile and the interquartile range of $T_{\mathrm{DD}}$, and (right) median wind profiles (barbs, with the full-length barb representing $10 \mathrm{kt} ; 1 \mathrm{kt} \approx 0.51 \mathrm{~m} \mathrm{~s}^{-1}$ ) at LD freezing rain event onset (purple) and end (orange) in (a) the NEUS/SECA, (b) the SCUS, and (c) the SEUS.

end to $+1.9^{\circ} \mathrm{C}(3 \mathrm{~h})^{-1}$ (Fig. $\left.7 \mathrm{~b}\right)$, and while this change is not statistically significant for $p<0.01$, the proportion of events observing CAA at this level increases from $7 \%$ at onset to $24 \%$ at event end. Freezing rain is followed by frozen precipitation after $23 \%$ of events, suggesting that in some cases CAA becomes sufficiently strong aloft to completely erode the warm layer.

\section{b. South-central United States}

Freezing rain events tend to follow a much different thermodynamic evolution in the SCUS than in the NEUS/SECA. The SCUS observes the deepest and warmest LD onset warm layers of the three focus regions (Figs. 4d,e), with a median warm layer depth of $1793 \mathrm{~m}$, more than twice that of the NEUS/SECA, and $T_{\max }$ of $5.6^{\circ} \mathrm{C}$. The median onset cold layer is shallower (630 $\mathrm{m}$ deep) than over the NEUS/SECA, though $T_{\min }$ is nearly as cold $\left(-4.6^{\circ} \mathrm{C}\right)$. Onset surface temperatures are relatively warm, with regional mean (median) values of $-1.7^{\circ} \mathrm{C}\left(-1.0^{\circ} \mathrm{C}\right)$ (Fig. 6a). These characteristics produce a sharp transition between the cold and warm layers (Fig. 5b).

Consistent with these warm precursor conditions, $32 \%$ of LD events are preceded by liquid precipitation, while only $16 \%$ are preceded by frozen precipitation (Table 1). More commonly, events are preceded by no precipitation $(43 \%)$ as a result of subsaturated precursor conditions aloft, as evidenced by the large spread in $T_{\mathrm{DD}}$ profiles (Fig. 5b). Similarly, an additional $14 \%$ of events are preceded by freezing drizzle, which is often formed in shallow saturated layers near the surface topped by drier air aloft (Bocchieri 1980; Huffman and Norman 1988; Rauber et al. 2001).

The composite north-northeasterly winds near the surface (Fig. 5b) are associated with the strongest median surface CAA $\left[-0.4^{\circ} \mathrm{C}(3 \mathrm{~h})^{-1}\right]$ of the three regions (Fig. 7a). Additionally, surface dry-air advection $(-\mathbf{v} \cdot \nabla w<0)$ is observed at the onset of $73 \%$ of LD events (cf. $63 \%$ in the NEUS/SECA), increasing to $84 \%$ by event end (Fig. $7 \mathrm{c}$ ). The replenishment of surface cold and dry air allows surface temperatures to remain nearly steady during events, with a mean (median) temperature change of $-0.1^{\circ} \mathrm{C}\left(0.0^{\circ} \mathrm{C}\right)$ (Fig. 6c). Only $31 \%$ of LD events end with a surface temperature $\geq 0{ }^{\circ} \mathrm{C}$.

In the warm layer, the median onset wind profile veers from southeasterly to southwesterly with height (Fig. 5b), with median WAA at the level of $T_{\max }^{250-2500 \mathrm{~m}}$ of $+1.8^{\circ} \mathrm{C}(3 \mathrm{~h})^{-1}$ at onset (Fig. $\left.7 \mathrm{~b}\right)$. By event end, veering in the warm layer becomes less pronounced (Fig. 5b) and median temperature advection weakens significantly to $+0.7^{\circ} \mathrm{C}(3 \mathrm{~h})^{-1}$ (Fig. $7 \mathrm{~b}$ ). The percentage of events for which CAA is observed at the level of $T_{\max }^{250-2500 \mathrm{~m}}$ increases from $15 \%$ at onset to $40 \%$ by event end.

The median warm layer cools and becomes shallower from onset to end, with $T_{\max }$ falling to $3.6^{\circ} \mathrm{C}$ and the median 
a) Mean LD onset temperature $\left({ }^{\circ} \mathrm{C}\right)$

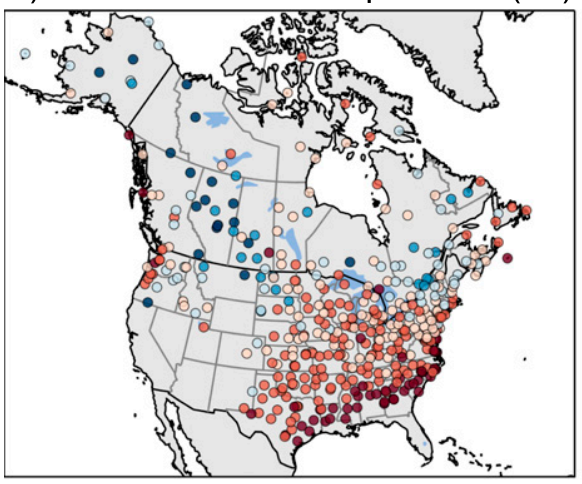

c) Mean $\Delta T$ during LD events $\left({ }^{\circ} \mathrm{C}\right)$

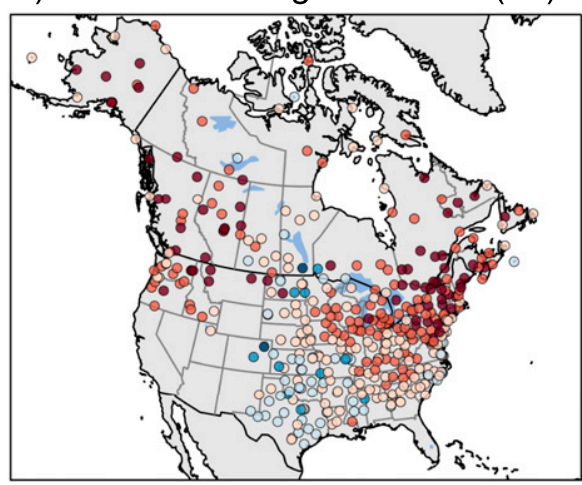

b) Mean LD onset $\operatorname{TDD}\left({ }^{\circ} \mathrm{C}\right)$
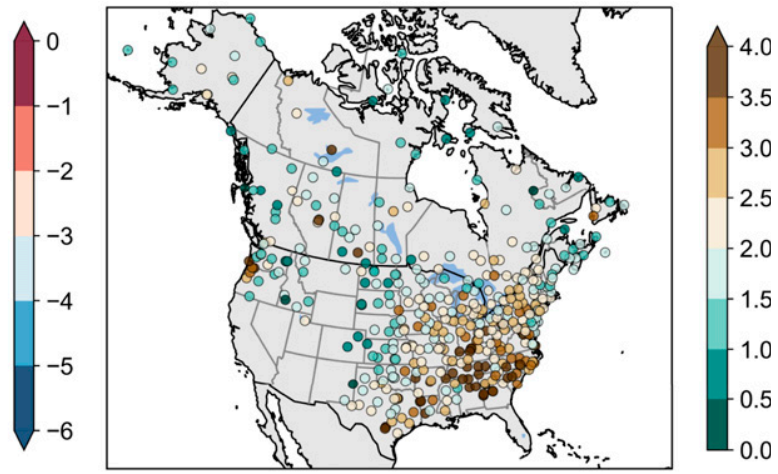

d) Mean $\triangle T_{D D}$ during LD events $\left({ }^{\circ} \mathrm{C}\right)$

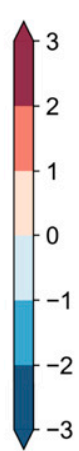

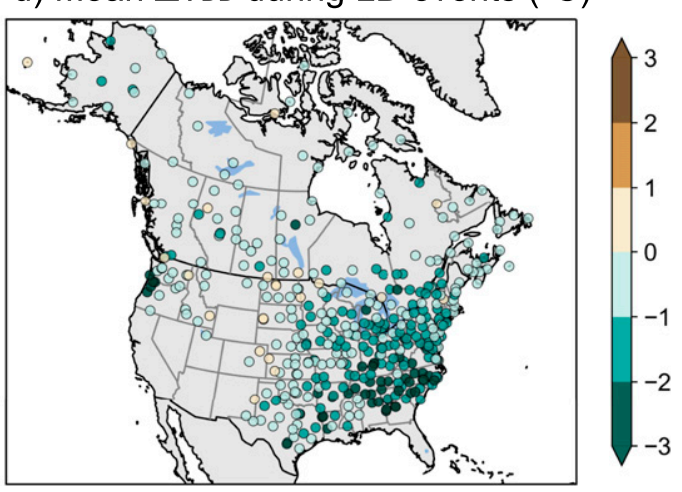

FIG. 6. Surface temperature and moisture characteristics associated with LD events at each station in our dataset: (a) the mean temperature observed at the onset of $\mathrm{LD}$ freezing rain events $\left({ }^{\circ} \mathrm{C}\right),(\mathrm{b})$ the mean dewpoint depression $T_{\mathrm{DD}}$ observed at LD event onset, (c) the mean temperature change during LD events, calculated by subtracting the temperature at event end from the temperature at onset for each event and taking the mean among all events at each station, and (d) the mean dewpoint depression change during LD events. Only stations that have observed at least five LD events are plotted.

depth decreasing significantly to $1059 \mathrm{~m}$ (Figs. 4d,e). The proportion of soundings lacking a warm layer increases from only $4 \%$ at onset to $16 \%$ at event end. The erosion of the warm layer and maintenance of surface temperatures $<0^{\circ} \mathrm{C}$ cause $25 \%$ of $L D$ events in the SCUS to end in a transition from freezing rain to frozen precipitation (Table 1 ).

Substantial drying occurs above $\sim 2000 \mathrm{~m}$ AGL during events (Fig. 5b), and the SCUS is the only region in which cloud characteristics undergo statistically significant changes for $p<0.01$ (Fig. 8). The proportion of events with dry-air advection at the level of $T_{\max }^{250-2500 \mathrm{~m}}$ doubles from $21 \%$ at onset to $42 \%$ by event end (Fig. 7d). The column above the cold layer dries significantly, with the median cloud depth decreasing from 4906 to $3720 \mathrm{~m}$ (Fig. 8a). Thus, LD events over the SCUS are most commonly followed by no precipitation ( $32 \%$ of events, Table 1 ). As the cloud layer

TABLE 1. Percentage of LD freezing rain events followed and preceded by snow/ice pellets (SN/IP), rain/drizzle (RA/DZ), freezing drizzle (FZDZ), or no precipitation (NP) among all surface stations in the NEUS/SECA, SCUS, and SEUS regions. Bold text indicates the most common type for each period and region. Sums of percentages for each region may be $>100 \%$, as mixes can be counted for multiple categories. Only observations from 1979 to 1994 (roughly the preautomation era) are used.

\begin{tabular}{|c|c|c|c|c|c|c|}
\hline \multirow[b]{2}{*}{ Type } & \multicolumn{3}{|c|}{ Before event onset } & \multicolumn{3}{|c|}{ After event end } \\
\hline & NEUS/SECA & SCUS & SEUS & NEUS/SECA & SCUS & SEUS \\
\hline SN/IP & $51 \%$ & $16 \%$ & $43 \%$ & $23 \%$ & $25 \%$ & $14 \%$ \\
\hline $\mathrm{RA} / \mathrm{DZ}$ & $12 \%$ & $32 \%$ & $34 \%$ & $43 \%$ & $18 \%$ & $45 \%$ \\
\hline FZDZ & $12 \%$ & $15 \%$ & $7 \%$ & $16 \%$ & $31 \%$ & $21 \%$ \\
\hline NP & $31 \%$ & $43 \%$ & $26 \%$ & $22 \%$ & $32 \%$ & $24 \%$ \\
\hline
\end{tabular}



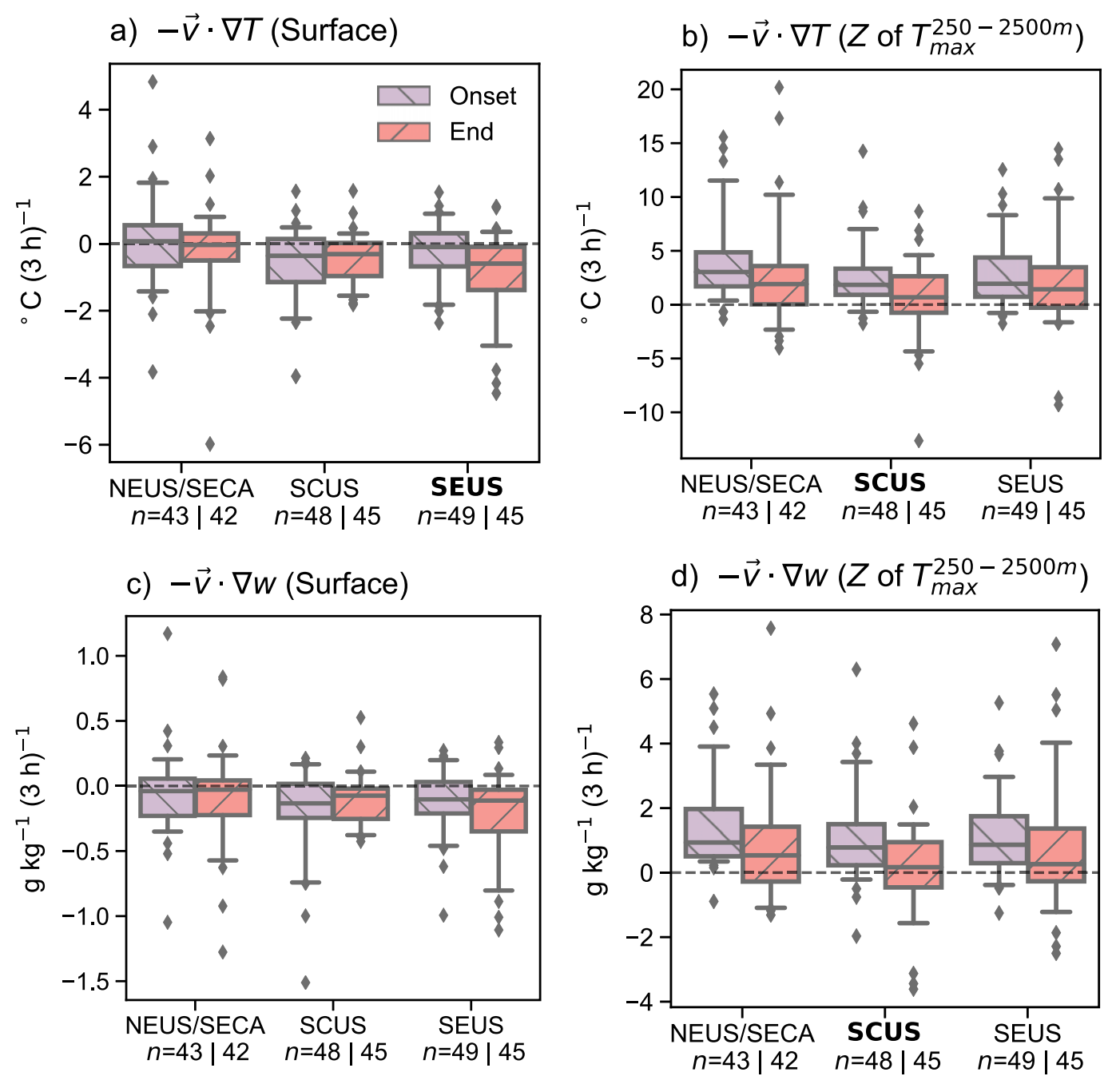

FIG. 7. Boxplots as in Fig. 4, except showing distributions of (a),(b) temperature advection $\left[-\mathbf{v} \cdot \nabla T ;{ }^{\circ} \mathrm{C}(3 \mathrm{~h})^{-1}\right]$ and (c),(d) advection of water vapor mixing ratio $\left[-\mathbf{v} \cdot \nabla w ; \mathrm{g} \mathrm{kg}^{-1}(3 \mathrm{~h})^{-1}\right]$ calculated from the CFSR for events with observed sounding data at LD event onset and end at the (left) surface (advection of 2-m temperature/mixing ratio by the $10-\mathrm{m}$ wind) and (right) at the altitude of the maximum temperature in the 250-2500 $\mathrm{m}$ AGL layer.

becomes shallower, the median cloud top temperature rises significantly, from $-16.8^{\circ} \mathrm{C}$ at onset to $-7.1^{\circ} \mathrm{C}$ at event end (Fig. 8b). Many of these shallower cloud layers are too warm to support ice nucleation, and $31 \%$ of LD events over the SCUS are followed by freezing drizzle.

\section{c. Southeastern United States}

Thermodynamic profiles observed during LD events in the SEUS share characteristics with those of both the NEUS/SECA and SCUS. The median onset cold layer is nearly as cold $\left(T_{\min }\right.$ of $\left.-4.4^{\circ} \mathrm{C}\right)$ and deep $(913 \mathrm{~m})$ as in the NEUS/SECA (Figs. 4a,b), though onset surface temperatures are higher, with a mean (median) of $-1.5^{\circ} \mathrm{C}$ $\left(-1.1^{\circ} \mathrm{C}\right)$ (Fig. 6a).
While the median onset warm layer is deeper over the SEUS than the NEUS/SECA $(1144 \mathrm{~m})$, it is relatively cool, with a median $T_{\max }$ of $2.3^{\circ} \mathrm{C}$ (Figs. $4 \mathrm{~d}, \mathrm{e}$ ). Freezing rain onset is most commonly associated with the development of the warm layer, with frozen precipitation preceding $43 \%$ of LD events here (Table 1 ). In $34 \%$ of events, however, freezing rain is preceded by liquid precipitation. In these cases, warm air is evidently already in place aloft but the surface has not yet cooled below $0^{\circ} \mathrm{C}$ when precipitation began.

Onset cold layers in the SEUS are particularly dry, with the 75th percentile of $T_{\mathrm{DD}}$ reaching $\approx 6^{\circ} \mathrm{C}$ just above the surface (Fig. 5c). The SEUS observes the largest surface $T_{\mathrm{DD}}$ values of the three regions at onset, with a mean (median) of $2.9^{\circ} \mathrm{C}\left(2.2^{\circ} \mathrm{C}\right)$ (Fig. $\left.6 \mathrm{~b}\right)$. A total of $60 \%$ 
a) Cloud depth (m)

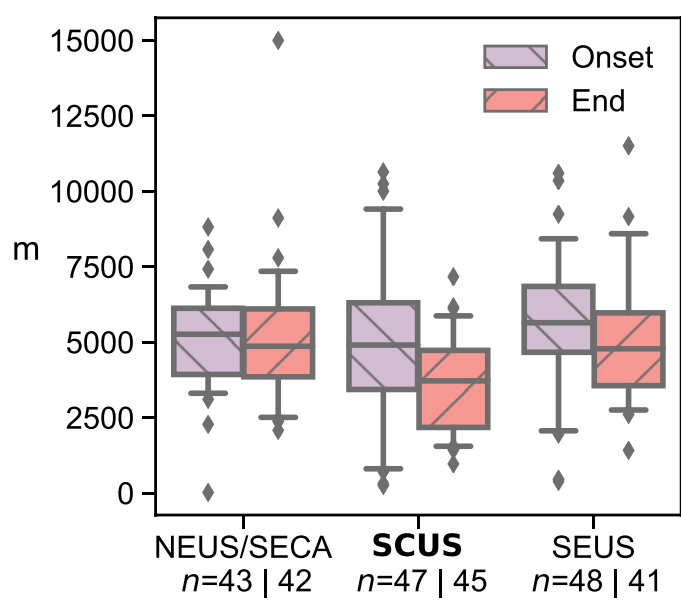

b) Cloud top temperature $\left({ }^{\circ} \mathrm{C}\right)$

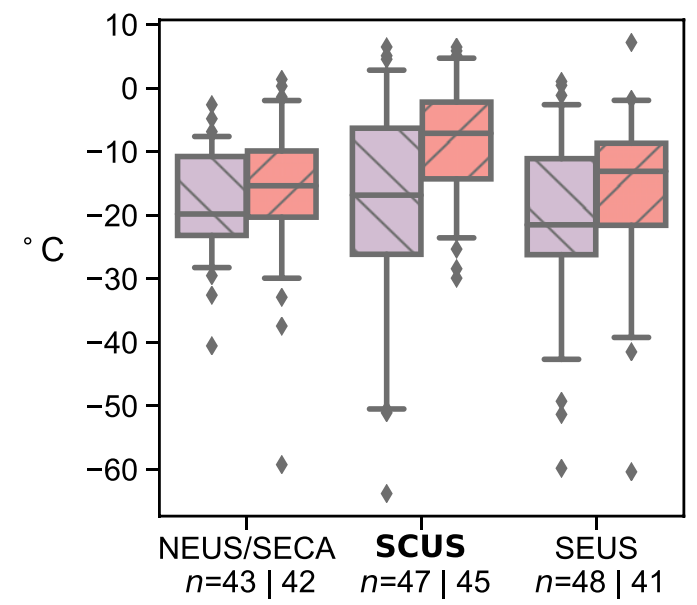

FIG. 8. Boxplots as in Fig. 4, except showing distributions of (a) the cloud layer depth (m) and (b) cloud top temperature $\left({ }^{\circ} \mathrm{C}\right)$ calculated from observed soundings for each region at LD event onset and end. Criteria for identifying cloud layers are discussed in section $2 \mathrm{c}$.

of LD events have onset surface $T_{\mathrm{DD}} \geq 2^{\circ} \mathrm{C}$, compared with $51 \%$ of events in the NEUS/SECA and $43 \%$ in the SCUS.

The cold layer is characterized by persistent northeasterly winds (Fig. 5c). Robbins and Cortinas (2002) found that while strong surface CAA occurs prior to freezing rain in this region, CAA during freezing rain is weak. Consistent with their findings, median surface temperature advection is $-0.1^{\circ} \mathrm{C}(3 \mathrm{~h})^{-1}$, with $57 \%$ of events observing surface CAA at onset. This CAA strengthens significantly to $-0.6^{\circ} \mathrm{C}(3 \mathrm{~h})^{-1}$ by event end, with the proportion of events observing CAA increasing to $80 \%$ (Fig. 7a). Additionally, $69 \%$ of events have surface dry-air advection at onset, increasing to $84 \%$ by event end (Fig. 7c).
Veering winds aloft (Fig. 5c) are associated with median temperature advection at the level of $T_{\max }^{250-2500 \mathrm{~m}}$ of $+1.9^{\circ} \mathrm{C}(3 \mathrm{~h})^{-1}$ at onset (Fig. $7 \mathrm{~b}$ ). The warm layer undergoes substantial warming from onset to end, with the median depth increasing to $1505 \mathrm{~m}$ and $T_{\max }$ rising to $+4.8^{\circ} \mathrm{C}$ (Figs. $4 \mathrm{~d}$,e). As the warm layer deepens, the cold layer becomes significantly shallower by event end, with the median depth falling to $620 \mathrm{~m}$ (Fig. 4a). The median $T_{\min }$ also increases slightly to $-3.5^{\circ} \mathrm{C}$, though this change is not statistically significant for $p<0.01$ (Fig. 4b). The greatest cold layer changes are limited to the uppermost portions of the layer (Fig. 5c), with a mean (median) surface temperature change of just $+0.8^{\circ} \mathrm{C}\left(+0.6^{\circ} \mathrm{C}\right)($ Fig. $6 \mathrm{c})$. The surface $T_{\mathrm{DD}}$ decreases by a mean (median) of $1.8^{\circ} \mathrm{C}\left(1.1^{\circ} \mathrm{C}\right)$ from event onset to end (Fig. 6d) as evaporation occurs and the nearsurface environment approaches saturation.

Despite evaporative cooling and surface CAA, only weak heating (e.g., via the release of latent heat of fusion when rain freezes) is required to bring the relatively warm SEUS onset surface temperatures to $0^{\circ} \mathrm{C}$ and transition precipitation to rain. Indeed, $54 \%$ of LD events end with surface temperatures $\geq 0{ }^{\circ} \mathrm{C}$, and freezing rain transitions to rain/drizzle following $45 \%$ of events (Table 1).

Additionally, the median cloud depth decreases from $5646 \mathrm{~m}$ at event onset to $4782 \mathrm{~m}$ at event end, with the median cloud top temperature rising from $-21.5^{\circ}$ to $-13.1^{\circ} \mathrm{C}$, though these changes are not significant for $p<0.01$ (Figs. 8a,b). Drying aloft results in LD events commonly ending in freezing drizzle ( $21 \%$ of events) or no precipitation ( $24 \%$ of events). As a consequence of the considerable warming aloft during LD events here, frozen precipitation follows only $14 \%$ of events, the lowest proportion of the three regions (Table 1).

\section{Discussion}

\section{a. Regional climatology of long-duration freezing rain}

Prior studies have found that freezing rain most often occurs to the north of a surface warm front in the NEUS/ SECA, where freezing rain and LD events occur most frequently (Figs. 1a,b) (e.g., Rauber et al. 2001; Ressler et al. 2012; Castellano 2012). The archetypal thermodynamic evolution found here is consistent with this, with the warm-frontal inversion producing the warm layer aloft as the front moves northward. The regional maximum in LD event frequency is likely related to a wintertime storm track that often places cyclones and their associated warm fronts over the Great Lakes region (Zishka and Smith 1980). 
The importance of topography and water bodies on freezing rain events is well known (e.g., Bernstein 2000), and these effects are evident in our climatology. While most locations in the NEUS/SECA do not observe strong surface CAA during events, terrain features that either trap or channel cold air result in local maxima in LD event frequency. A given freezing rain event in these areas may persist for longer periods than elsewhere. For example, the St. Lawrence River Valley in Quebec contains three of the five stations observing the maximum median of $3 \mathrm{LD}$ events $\mathrm{yr}^{-1}$ (Fig. 1b). Previous research (e.g., Carrera et al. 2009; Razy et al. 2012; Ressler et al. 2012) has demonstrated that pressure-driven wind channeling down the valley supports persistent surface CAA that maintains the cold layer during freezing rain events there.

Conditions favorable for freezing rain occur more rarely over the SCUS than in the NEUS/SECA (Fig. 1a). However, when these conditions do occur, they sometimes support particularly long-duration events (Fig. 1d). Sanders et al. (2013) and Mullens et al. (2016b) found that ice storms occur here as an arctic anticyclone and its associated cold front progress southward through the region, undercutting warm, moist air in place aloft. Our composite onset soundings (Fig. 5b) show evidence of a recent cold-frontal passage, with an abrupt transition between the warm and cold layers and north-northeasterly median winds at the surface becoming southerly aloft.

The relatively high frequency of $\geq 18$-h events in the SCUS (Fig. 1d) is likely the result of the region's geographic location. The Gulf of Mexico to the south is a source of warm, moist air that sustains the warm layer (e.g., Mullens et al. 2016a), while the Rocky Mountains to the west force cold/dry ageostrophic northerlies into the SCUS as anticyclones move southward out of Canada (e.g., Colle and Mass 1995). This advection of cold and dry air sustains the cold layer during LD events, preventing the surface from reaching $0^{\circ} \mathrm{C}$.

Finally, large-scale effects of topography on freezing rain events are especially evident in the SEUS, where freezing rain most commonly occurs during Appalachian CAD (e.g., Bernstein 2000; Rauber et al. 2001; Robbins and Cortinas 2002). The median temperature and wind profiles found at LD event onset are consistent with those observed during CAD (e.g., Bell and Bosart 1988) (Fig. 5c). The SEUS is noteworthy for the propensity of freezing rain events to be LD there (Fig. 1c), which may result from the average 25-30-h duration of wintertime CAD events themselves (Rackley and Knox 2016).

Our findings expand on the results of Robbins and Cortinas (2002), who studied freezing rain observations at six upper-air sites. They noted large variations in the typical warm and cold layer characteristics during freezing rain from one station to another. For example, they found the median cold layer to be twice as deep at Albany, New York (KALB, $1000 \mathrm{~m}$ ) than at Buffalo, New York (KBUF, $503 \mathrm{~m}$ ), and attributed this difference to cold-air trapping within the Hudson Valley at KALB. Our results suggest that while large interregional variability exists in the thermodynamic evolution of LD freezing rain events, coherent patterns are typical of each focus region. Local variations are largely dependent on the aforementioned terrain features, with the principal effects of these features being in the cold layer. The propensity for certain evolutions in these regions suggests potential value in developing regional forecasting techniques tailored to these thermodynamic processes.

\section{b. Regional thermodynamic evolution of long-duration freezing rain events}

Lackmann et al. (2002) demonstrated that the release of latent heat of fusion when rain freezes at the surface can be an important effect in the cold layer, particularly when other processes (temperature advection, evaporative cooling, etc.) are small. We can estimate the effect of this latent heat release using Eq. (4) from Lackmann et al. (2002):

$$
\Delta T \cong \frac{F_{A} L_{f} \rho_{l} R_{m}}{M\left(C_{p}+L_{v} \frac{\partial q_{s}}{\partial T}\right)},
$$

where $T$ is the dry-bulb temperature, $F_{A}$ is the fraction $(0-1)$ of latent heat release imparted to the air as opposed to into the ground, $L_{f}$ is the latent heat of fusion, $\rho_{l}$ is the density of liquid water, $R_{m}$ is the depth of liquid equivalent precipitation (m), $M$ is the mass of air per unit area through which the heat is transferred, $C_{p}$ is the specific heat of air at constant pressure, $L_{v}$ is the latent heat of vaporization, and $q_{s}$ is the saturation specific humidity. We calculate an upper bound for $\Delta T$ in each focus region using $F_{A}=1$, with all of the released heat warming the air. ${ }^{2}$ We estimate $M$ using the median cold layer depth and layer-average temperature for each region at $\mathrm{LD}$ onset and use an example precipitation rate of $0.05 \mathrm{in} . \mathrm{h}^{-1}$ for $R_{M}$. The calculated heating rates (Table 2 ) are similar in magnitude to temperature advection, and thus the effects of freezing cannot be ignored.

\footnotetext{
${ }^{2}$ In situations where the ground is relatively warm (near or $>0^{\circ} \mathrm{C}$ ) or is insulated by snow cover, $F_{A}$ will be close to 1 (Lackmann et al. 2002). When the ground is bare and the soil temperature is well below $0^{\circ} \mathrm{C}$, a larger portion of the released latent heat will be transferred into the ground.
} 
We find the largest heating rates in the SCUS, where the onset cold layer is shallowest and thus the heat is distributed over a relatively small mass (Table 2). Given these rates, the SCUS cold layer could be eroded (i.e., warmed to $0^{\circ} \mathrm{C}$ ) after $\approx 8 \mathrm{~h}$ by freezing alone. However, the median $-0.4^{\circ} \mathrm{C}(3 \mathrm{~h})^{-1}$ surface CAA would substantially offset this heating, with the persistent dry-air advection (Fig. 7c) also potentially supporting continued near-surface evaporative cooling. This agrees with the small surface temperature changes during LD events in this region (Fig. 6c).

In the SEUS, complete cold layer erosion by freezing would take $\approx 12 \mathrm{~h}$, however, onset cold layers there have the largest $T_{\mathrm{DD}}$ values of the three focus regions (Figs. 5c, 6b). Because $L_{v}$ is an order of magnitude larger than $L_{f}$, evaporative cooling will offset low-level heating due to freezing, delaying the erosion of the cold layer and subsequent transition from freezing rain to rain. The weak surface cold- and dry-air advection typical of events in the SEUS further delays erosion. Bell and Bosart (1988) noted the importance of evaporative cooling during CAD, attributing $\approx 30 \%$ of the cooling that generated the cold dome during a March 1985 CAD event to evaporation.

The NEUS/SECA differs from the other regions in that no large-scale compensatory mechanism to offset the heat released by freezing is evident. The onset cold layer, unlike in the SEUS, tends to be near-saturated (Fig. 5a), and strong surface CAA is uncommon (Fig. 7a). The NEUS/SECA observes the deepest median onset cold layer of the three regions, resulting in the lowest rates of heating by freezing (Table 2 ) and requiring $\approx 13 \mathrm{~h}$ for complete cold layer erosion by freezing alone. However, the WAA aloft acts to erode the cold layer from above, decreasing the mass of the column through which the heat is distributed and thus increasing the rate of heating and accelerating erosion. The typical evolution whereby LD events end when the surface temperature reaches $0^{\circ} \mathrm{C}$ suggests the role of the release of latent heat of fusion may be particularly important in the NEUS/SECA.

The extraction of latent heat of fusion due to melting in the warm layer appears to be less important in most regions, as persistent WAA is common aloft (Fig. 7b). The SCUS is the only region where temperature advection at the level of $T_{\max }^{250-2500 \mathrm{~m}}$ and the warm layer depth decrease significantly by event end (Figs. 4d,7b), with complete erosion occurring in the $25 \%$ of events that transition to frozen precipitation (Table 1). Kain et al. (2000) derived a simple expression for the amount of liquid equivalent precipitation required to completely erode the warm layer:

$$
D(\mathrm{~cm}) \approx \frac{-\delta T \times \delta P}{193},
$$

TABLE 2. Estimated heating rates from the release of latent heat of fusion at the surface calculated using Eq. (1) with a $0.05 \mathrm{in.} \mathrm{h}^{-1}$ $\left(1.27 \mathrm{~mm} \mathrm{~h}^{-1}\right)$ precipitation rate. Rates are calculated for the NEUS/ SECA, SCUS, and SEUS using the displayed regional median LD onset cold layer characteristics, with the mass per unit area through which the latent heat release is transferred estimated using the median depth $(\mathrm{m})$ and layer-average temperature $\left({ }^{\circ} \mathrm{C}\right)$ of the cold layer. Also displayed are the median surface temperature advection values discussed in section 4 , for comparison.

\begin{tabular}{|c|c|c|c|}
\hline & NEUS/SECA & SCUS & SEUS \\
\hline Median cold layer depth (m) & 1012 & 630 & 913 \\
\hline Median layer-average $T\left({ }^{\circ} \mathrm{C}\right)$ & -2.8 & -2.8 & -2.9 \\
\hline $\begin{array}{l}\text { Median cold layer mass per unit } \\
\text { area }\left(\mathrm{kg} \mathrm{m}^{-2}\right)\end{array}$ & 1220 & 780 & 1110 \\
\hline $\begin{array}{l}\text { Heating due to release of } \\
\qquad L_{f}\left[{ }^{\circ} \mathrm{C}(3 \mathrm{~h})^{-1}\right]\end{array}$ & +0.7 & +1.0 & +0.7 \\
\hline $\begin{array}{l}\text { Median surface }-\mathbf{v} \cdot \nabla T \\
{\left[{ }^{\circ} \mathrm{C}(3 \mathrm{~h})^{-1}\right]}\end{array}$ & +0.1 & -0.4 & -0.1 \\
\hline
\end{tabular}

where $\delta T$ is the negative of the mean wet-bulb temperature $\left({ }^{\circ} \mathrm{C}\right)$ in the warm layer and $\delta P$ is the pressure depth $(\mathrm{hPa})$ of the layer. Using the median values at $\mathrm{LD}$ onset over the SCUS $\left(\delta T=-2.2^{\circ} \mathrm{C}, \delta P=132 \mathrm{hPa}\right)$, we calculate $D=1.5 \mathrm{~cm}$ ( $0.59 \mathrm{in}$.). Complete erosion of the median warm layer due to melting would take at least $12 \mathrm{~h}$ for a $0.05 \mathrm{in} . \mathrm{h}^{-1}$ precipitation rate with no temperature advection. Heavier precipitation or CAA in the warm layer could accelerate erosion.

Finally, while the cloud cover associated with precipitation likely dampens its effects, surface temperature changes due to the diurnal cycle of solar radiation may also play a role in freezing rain event evolution. Cortinas et al. (2004) found that freezing rain occurs most frequently just prior to sunrise and least frequently in the midafternoon (see their Fig. 9). To examine the role of radiative heating in LD events, we perform a similar analysis to Cortinas et al. (2004) and examine the diurnal cycle of LD event onset and end times. We convert times to normalized solar time (NST) (Kelly et al. 1978, 1985), which divides the day into 12 daytime and 12 nighttime hours, with sunrise (sunset) always occurring at 0600 NST (1800 NST).

In all regions, $\mathrm{LD}$ events begin more often overnight than during the day, with a midday minimum $\left(\approx 3 \% \mathrm{~h}^{-1}\right)$ and a relatively steady $5 \% \mathrm{~h}^{-1}$ overnight (Fig. 9a). All regions observe a peak frequency in end times near sunrise (Fig. 9b). This peak is particularly pronounced in the SEUS and NEUS/SECA, where $25 \%$ and $21 \%$ of events end between sunrise and 0900 NST, respectively, while roughly half as many events end in the equally long 1500-1800 NST presunset period. Radiative heating at sunrise appears to be less important in the SCUS, where $17 \%$ of events end between 0600 and 0900 NST and a similar $15 \%$ end between 1500 and 1800 NST. 
a) LD event onset time

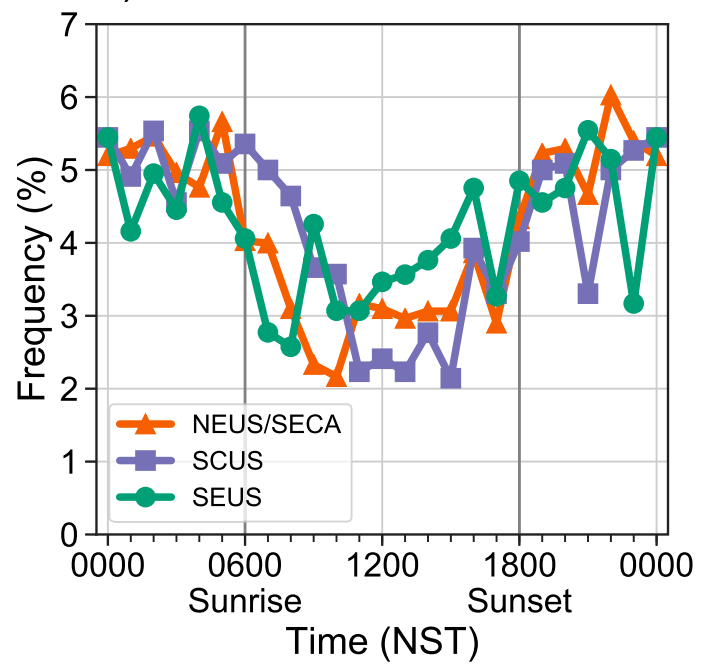

b) LD event end time

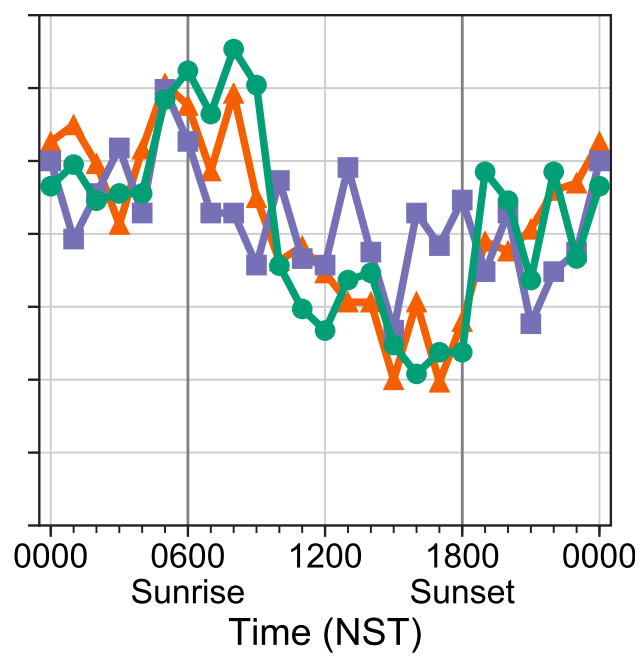

FIG. 9. Distribution (\%) of (a) LD event onset and (b) end times in normalized solar time (NST) for the NEUS/ SECA (orange lines/triangles), SCUS (purple lines/squares), and SEUS (green lines/circles). The method for conversion from UTC to NST is described in the text.

The interregional differences in the diurnal cycle of end times are consistent with our previous findings. The persistent surface CAA during LD events in the SCUS sustains surface temperatures $\leq 0^{\circ} \mathrm{C}$, even with latent and radiative heating effects. Conversely, the lack of strong surface CAA in the SEUS and NEUS/SECA cold layers make these regions more susceptible to any heating mechanism that may cause temperatures to rise to $0^{\circ} \mathrm{C}$. The effect of radiative heating on LD events therefore appears to be a nonnegligible, but secondary factor relative to those (onset temperature, advection, etc.) previously discussed.

The impact of these diabatic processes depends on the instantaneous precipitation rate, advection profile, and depths/temperatures of the warm and cold layers in which they are occurring. Future studies should consider a more detailed analysis of these rates, using soil/surface temperature measurements and thermodynamic profile observations and/or numerical model simulations. This could help constrain uncertain parameters such as $F_{A}$ in Eq. (1) and better quantify the roles of these processes during freezing rain events.

\section{Conclusions}

In this paper, we have presented the climatology of long-duration ( $\mathrm{LD}, \geq 6 \mathrm{~h}$ ) freezing rain events over North America from 1979-2016. From this climatology, we have identified three focus regions in which coherent surface and upper-air temperature/moisture characteristics support the persistence of these events, and have described the archetypal thermodynamic evolution of LD events in each region.

1) Freezing rain and LD events occur most frequently in the northeastern United States and southeastern Canada (NEUS/SECA).

- LD events there are most often preceded by snow/ ice pellets, as the atmospheric column tends to be cold prior to freezing rain onset.

- Strong lower-tropospheric WAA develops the warm layer, with continued warming aloft throughout events.

- Cold layers are eroded as a result of the WAA from above and the release of latent heat of fusion at the surface. Cold layer erosion can be delayed in locations with terrain features that support low-level CAA during events.

- By event end, surface temperatures commonly rise to $0^{\circ} \mathrm{C}$ and precipitation transitions from freezing rain to rain.

2) While freezing rain occurs less frequently in the south-central United States (SCUS) than in the NEUS/SECA, several of the top $1 \%$ of freezing rain events by duration (those lasting $\geq 18 \mathrm{~h}$ ) have occurred there.

- Precursor conditions tend to be warm, with particularly warm/deep onset warm layers aloft.

- LD events begin as surface temperatures fall below $0^{\circ} \mathrm{C}$ and/or as profiles saturate aloft, with no precipitation or rain/drizzle most commonly preceding freezing rain. 
- Persistent northerly winds produce cold- and dryair advection within the cold layer. The combination of cooling via CAA and evaporative cooling in the subsaturated air are generally sufficient to offset any latent heat release at the surface, and temperatures remain steady during events.

- Warm layers cool and profiles dry by event end, with precipitation commonly transitioning to snow/ice pellets, no precipitation, or freezing drizzle as this occurs.

3) Finally, the southeastern United States (SEUS) is the only region where $\mathrm{LD}$ events represent a majority of cases at many stations.

- As in the NEUS/SECA, LD events are most often preceded by frozen precipitation, with relatively cool onset warm layers.

- When freezing rain begins, large dewpoint depressions in the cold layer allow for evaporative cooling. This, combined with weak surface CAA, offsets the warming from the release of latent heat of fusion when rain freezes at the surface, delaying the erosion of the cold layer.

- As events progress, the warm layer deepens substantially and the cold layer is eroded from above due to strong WAA aloft.

- Onset surface temperatures are near $0^{\circ} \mathrm{C}$, and despite cooling via evaporation and CAA, LD events most commonly end as the surface reaches $0^{\circ} \mathrm{C}$ and freezing rain transitions to rain/drizzle.

Our results highlight particular characteristics that may be key to prolonging freezing rain in each region and merit increased attention from forecasters. For example, in the NEUS/SECA and SEUS, the onset cold layer characteristics appear to be particularly important, as a colder, deeper cold layer will take longer to erode via surface latent heat release and WAA aloft than a warmer, shallower one. In the SEUS, the role of evaporative cooling in offsetting latent heat released by freezing suggests that a drier onset cold layer may support longer-duration events. In the SCUS, where event cessation is more often associated with erosion of the warm layer, a warmer, deeper onset warm layer may delay the transition to snow/ice pellets. In a forthcoming study, we will explore these possibilities for each region through a comparison between the conditions associated with LD events and those associated with shorterduration cases.

While the typically light nature of freezing rain means that event duration is a primary factor in the severity of an event, future studies should consider examining additional variables such as precipitation amount. The recent arrival of routine ASOS ice accretion observations in the United States provides a promising dataset for objectively identifying severe events.

Finally, while we have discussed the archetypal thermodynamic evolutions in each region here, different evolutions do occur within each region. Examination of the various types of $L D$ events within a given region may be informative. One possibility is to distinguish events based on the phase transitions surrounding them, such as comparing NEUS/SECA events that ended in a transition to rain with those that ended in a transition to snow. Analysis of the thermodynamic and synoptic-dynamic patterns associated with each event type may provide forecasters with additional information that may be beneficial in producing more accurate predictions of freezing rain.

Acknowledgments. This work is supported by the Natural Sciences and Engineering Research Council of Canada (NSERC), through the Canadian Network for Regional Climate and Weather Processes (CNRCWP) and the Discovery Grant program. We thank Mr. Brian Barjenbruch, Mr. Philip Schumacher, and one anonymous reviewer for their insightful feedback that helped to greatly improve this manuscript.

\section{REFERENCES}

Baldwin, M., R. Treadon, and S. Contorno, 1994: Precipitation type prediction using a decision tree approach with NMCs mesoscale eta model. Preprints, 10th Conf. on Numerical Weather Prediction, Portland, OR, Amer. Meteor. Soc., 30-31.

Bell, G. D., and L. F. Bosart, 1988: Appalachian cold-air damming. Mon. Wea. Rev., 116, 137-161, https://doi.org/10.1175/15200493(1988)116<0137:ACAD>2.0.CO;2.

Benjamin, S. G., J. M. Brown, and T. G. Smirnova, 2016: Explicit precipitation-type diagnosis from a model using a mixedphase bulk cloud-precipitation microphysics parameterization. Wea. Forecasting, 31, 609-619, https://doi.org/10.1175/ WAF-D-15-0136.1.

Bernstein, B. C., 2000: Regional and local influences on freezing drizzle, freezing rain, and ice pellet events. Wea. Forecasting, 15, 485-508, https://doi.org/10.1175/1520-0434(2000)015<0485: RALIOF $>2.0 . \mathrm{CO} ; 2$.

Bocchieri, J. R., 1980: The objective use of upper air soundings to specify precipitation type. Mon. Wea. Rev., 108, 596-603, https://doi.org/10.1175/1520-0493(1980)108<0596:TOUOUA> 2.0.CO;2.

Bourgouin, P., 2000: A method to determine precipitation types. Wea. Forecasting, 15, 583-592, https://doi.org/10.1175/ 1520-0434(2000)015<0583:AMTDPT>2.0.CO;2.

Branick, M. L., 1997: A climatology of significant winter-type weather events in the contiguous United States, 1982-94. Wea. Forecasting, 12, 193-207, https://doi.org/10.1175/1520-0434(1997) 012<0193:ACOSWT>2.0.CO;2.

Brooks, C. F., 1920: The nature of sleet and how it is formed. Mon. Wea. Rev., 48, 69-72, https://doi.org/10.1175/1520-0493(1920) $48<69$ b:TNOSAH $>2.0$. CO; 2 .

Carrera, M. L., J. R. Gyakum, and C. A. Lin, 2009: Observational study of wind channeling within the St. Lawrence River 
Valley. J. Appl. Meteor. Climatol., 48, 2341-2361, https:// doi.org/10.1175/2009JAMC2061.1.

Castellano, C. M., 2012: Synoptic and mesoscale aspects of ice storms in the northeastern U.S. M.S. thesis, University at Albany, State University of New York, 149 pp.

Changnon, S. A., 2003: Characteristics of ice storms in the United States. J. Appl. Meteor., 42, 630-639, https://doi.org/10.1175/ 1520-0450(2003)042<0630:COISIT >2.0.CO;2.

Colle, B. A., and C. F. Mass, 1995: The structure and evolution of cold surges east of the Rocky Mountains. Mon. Wea. Rev., 123, 2577-2610, https://doi.org/10.1175/1520-0493(1995)123<2577: TSAEOC $>2.0 . \mathrm{CO} ; 2$.

Cortinas, J., Jr., 2000: A climatology of freezing rain in the Great Lakes region of North America. Mon. Wea. Rev., 128, 3574-3588, https://doi.org/10.1175/1520-0493(2001)129<3574: ACOFRI $>2.0 . \mathrm{CO} ; 2$

, B. C. Bernstein, C. C. Robbins, and J. Walter Strapp, 2004: An analysis of freezing rain, freezing drizzle, and ice pellets across the United States and Canada: 1976-90. Wea. Forecasting, 19, 377-390, https://doi.org/10.1175/1520-0434(2004) $019<0377$ :AAOFRF $>2.0 . \mathrm{CO} ; 2$.

DeGaetano, A. T., 2000: Climatic perspective and impacts of the 1998 northern New York and New England ice storm. Bull. Amer. Meteor. Soc., 81, 237-254, https://doi.org/10.1175/ 1520-0477(2000)081<0237:CPAIOT > 2.3.CO;2.

Forbes, G. S., D. W. Thomson, and R. A. Anthes, 1987: Synoptic and mesoscale aspects of an Appalachian ice storm associated with cold-air damming. Mon. Wea. Rev., 115, 564-591, https://doi.org/10.1175/1520-0493(1987)115<0564:SAMAOA > 2.0.CO;2.

Gay, D. A., and R. E. Davis, 1993: Freezing rain and sleet climatology of the southeastern USA. Climate Res., 3, 209-220, https://doi.org/10.3354/cr003209.

Gyakum, J. R., and P. J. Roebber, 2001: The 1998 ice stormAnalysis of a planetary-scale event. Mon. Wea. Rev., 129, 2983-2997, https://doi.org/10.1175/1520-0493(2001)129<2983: TISAOA $>2.0 . \mathrm{CO} ; 2$.

Huffman, G. J., and G. A. Norman, 1988: The supercooled warm rain process and the specification of freezing precipitation. Mon. Wea. Rev., 116, 2172-2182, https://doi.org/10.1175/15200493(1988)116<2172:TSWRPA $>2.0 . C O ; 2$.

Ikeda, K., M. Steiner, and G. Thompson, 2017: Examination of mixed-phase precipitation forecasts from the High-Resolution Rapid Refresh model using surface observations and sounding data. Wea. Forecasting, 32, 949-967, https://doi.org/10.1175/ WAF-D-16-0171.1.

Kain, J. S., S. M. Goss, and M. E. Baldwin, 2000: The melting effect as a factor in precipitation-type forecasting. Wea. Forecasting, 15, 700-714, https://doi.org/10.1175/1520-0434(2000)015<0700: TMEAAF $>2.0 . \mathrm{CO} ; 2$.

Kelly, D. L., J. T. Schaefer, R. P. McNulty, C. A. Doswell, and R. F. Abbey, 1978: An augmented tornado climatology. Mon. Wea. Rev., 106, 1172-1183, https://doi.org/10.1175/1520-0493(1978) 106<1172:AATC $>2.0$.CO;2.

,-- , and C. A. Doswell, 1985: Climatology of nontornadic severe thunderstorm events in the United States. Mon. Wea. Rev., 113, 1997-2014, https://doi.org/10.1175/1520-0493(1985) 113<1997:CONSTE > 2.0.CO;2.

Lackmann, G. M., K. Keeter, L. G. Lee, and M. B. Ek, 2002: Model representation of freezing and melting precipitation: Implications for winter weather forecasting. Wea. Forecasting, 17, 1016-1033, https://doi.org/10.1175/1520-0434(2003)017<1016: MROFAM $>2.0 . \mathrm{CO} ; 2$.
Lott, N., D. Ross, and A. Graumann, 1998: Eastern U.S. flooding and ice storm January 1998. Tech. Rep., NOAA/National Climatic Data Center, Asheville, NC, 6 pp.

May, R., S. Arms, P. Marsh, E. Bruning, and J. Leeman, 2017: Metpy: A Python package for meteorological data. Accessed 19 March 2019, https:/www.unidata.ucar.edu/software/metpy/, https://doi.org/10.5065/D6WW7G29.

McKay, G. A., and H. A. Thompson, 1969: Estimating the hazard of ice accretion in Canada from climatological data. J. Appl. Meteor., 8, 927-935, https://doi.org/10.1175/1520-0450(1969) $008<0927$ :ETHOIA $>2.0$. CO;2.

Meisinger, C. L., 1920: The precipitation of sleet and the formation of glaze in the eastern United States, January 20 to 25, 1920, with remarks on forecasting. Mon. Wea. Rev., 48, 73-80, https://doi.org/10.1175/1520-0493(1920)48<73b:TPOSAT $>$ 2.0.CO;2.

Mullens, E. D., L. M. Leslie, and P. J. Lamb, 2016a: Impacts of Gulf of Mexico SST anomalies on Southern Plains freezing precipitation: ARW sensitivity study of the 28-30 January 2010 winter storm. J. Appl. Meteor. Climatol., 55, 119-143, https:// doi.org/10.1175/JAMC-D-14-0289.1.

, — - and — 2016b: Synoptic pattern analysis and climatology of ice and snowstorms in the southern Great Plains, 1993-2011. Wea. Forecasting, 31, 1109-1136, https://doi.org/ 10.1175/WAF-D-15-0172.1.

NOAA, 1998: Automated Surface Observing System (ASOS) User's Guide. Tech. Rep., National Oceanic and Atmospheric Administration, $61 \mathrm{pp}$.

Rackley, J. A., and J. A. Knox, 2016: A climatology of southern Appalachian cold-air damming. Wea. Forecasting, 31, 419432, https://doi.org/10.1175/WAF-D-15-0049.1.

Ralph, F. M., and Coauthors, 2005: Improving short-term $(0-48 \mathrm{~h})$ cool-season quantitative precipitation forecasting. Bull. Amer. Meteor. Soc., 86, 1619-1632, https://doi.org/10.1175/ BAMS-86-11-1619.

Ramer, J., 1993: An empirical technique for diagnosing precipitation type from model output. Fifth Int. Conf. on Aviation Weather Systems, Vienna, VA, Amer. Meteor. Soc., 227-230.

Rauber, R. M., L. S. Olthoff, M. K. Ramamurthy, and K. E. Kunkel, 2000: The relative importance of warm rain and melting processes in freezing precipitation events. J. Appl. Meteor., 39, 1185-1195, https://doi.org/10.1175/1520-0450(2000)039<1185: TRIOWR $>2.0 . \mathrm{CO} ; 2$.

,,,--- D. Miller, and K. E. Kunkel, 2001: A synoptic weather pattern and sounding-based climatology of freezing precipitation in the United States east of the Rocky Mountains. J. Appl. Meteor., 40, 1724-1747, https://doi.org/10.1175/ 1520-0450(2001)040<1724:ASWPAS >2.0.CO;2.

Razy, A., S. M. Milrad, E. H. Atallah, and J. R. Gyakum, 2012: Synoptic-scale environments conducive to orographic impacts on cold-season surface wind regimes at Montreal, Quebec. J. Appl. Meteor. Climatol., 51, 598-616, https://doi.org/10.1175/ JAMC-D-11-0142.1.

Reeves, H. D., 2016: The uncertainty of precipitation-type observations and its effect on the validation of forecast precipitation type. Wea. Forecasting, 31, 1961-1971, https://doi.org/10.1175/ WAF-D-16-0068.1.

_ K. L. Elmore, A. Ryzhkov, T. Schuur, and J. Krause, 2014: Sources of uncertainty in precipitation-type forecasting. Wea. Forecasting, 29, 936-953, https://doi.org/10.1175/WAFD-14-00007.1.

Ressler, G. M., S. M. Milrad, E. H. Atallah, and J. R. Gyakum, 2012: Synoptic-scale analysis of freezing rain events in 
Montreal, Quebec, Canada. Wea. Forecasting, 27, 362-378, https://doi.org/10.1175/WAF-D-11-00071.1.

Richwien, B. A., 1980: The damming effect of the southern Appalachians. Natl. Wea. Dig., 5 (1), 2-12.

Robbins, C. C., and J. V. Cortinas, 2002: Local and synoptic environments associated with freezing rain in the contiguous United States. Wea. Forecasting, 17, 47-65, https://doi.org/ 10.1175/1520-0434(2002)017<0047:LASEAW>2.0.CO;2.

Roebber, P. J., and J. R. Gyakum, 2003: Orographic influences on the mesoscale structure of the 1998 ice storm. Mon. Wea. Rev., 131, 27-50, https://doi.org/10.1175/1520-0493(2003)131<0027: OIOTMS $>2.0 . \mathrm{CO} ; 2$.

Ryerson, C. C., and A. C. Ramsay, 2007: Quantitative ice accretion information from the Automated Surface Observing System. J. Appl. Meteor. Climatol., 46, 1423-1437, https://doi.org/10.1175/ JAM2535.1.

Saha, S., and Coauthors, 2010: The NCEP Climate Forecast System Reanalysis. Bull. Amer. Meteor. Soc., 91, 1015-1057, https:// doi.org/10.1175/2010BAMS3001.1.

Sanders, K. J., and B. L. Barjenbruch, 2016: Analysis of ice-toliquid ratios during freezing rain and the development of an ice accumulation model. Wea. Forecasting, 31, 1041-1060, https://doi.org/10.1175/WAF-D-15-0118.1.

_ C. Gravelle, J. Gagan, and C. Graves, 2013: Characteristics of major ice storms in the central United States. J. Oper. Meteor., 1, 100-113, https://doi.org/10.15191/nwajom.2013.0110.

Smith, A., N. Lott, and R. Vose, 2011: The integrated surface database: Recent developments and partnerships. Bull. Amer. Meteor. Soc., 92, 704-708, https://doi.org/10.1175/ 2011BAMS3015.1.
Stewart, R. E., 1985: Precipitation types in winter storms. Pure Appl. Geophys., 123, 597-609, https://doi.org/10.1007/BF00877456.

_ Mon. Wea. Rev., 115, 1270-1280, https://doi.org/10.1175/15200493(1987)115<1270:FPIWS > 2.0.CO;2.

Stuart, R., and G. Isaac, 1999: Freezing precipitation in Canada. Atmos.-Ocean, 37, 87-102, https://doi.org/10.1080/ 07055900.1999 .9649622$.

Thériault, J. M., R. E. Stewart, and W. Henson, 2010: On the dependence of winter precipitation types on temperature, precipitation rate, and associated features. J. Appl. Meteor. Climatol., 49, 1429-1442, https://doi.org/10.1175/2010JAMC2321.1.

Wexler, R., R. J. Reed, and J. Honig, 1954: Atmospheric cooling by melting snow. Bull. Amer. Meteor. Soc., 35, 48-51, https:// doi.org/10.1175/1520-0477-35.2.48.

Whiteman, C. D., and J. C. Doran, 1993: The relationship between overlying synoptic-scale flows and winds within a valley. J. Appl. Meteor., 32, 1669-1682, https://doi.org/10.1175/15200450(1993)032<1669:TRBOSS > 2.0.CO;2.

Wilks, D. S., 2011: Statistical Methods in the Atmospheric Sciences. 3rd ed. International Geophysics Series, Vol. 100, Academic Press, 704 pp.

Zerr, R. J., 1997: Freezing rain: An observational and theoretical study. J. Appl. Meteor., 36, 1647-1661, https://doi.org/10.1175/ 1520-0450(1997)036<1647:FRAOAT >2.0.CO;2.

Zishka, K. M., and P. J. Smith, 1980: The climatology of cyclones and anticyclones over North America and surrounding ocean environs for January and July, 1950-77. Mon. Wea. Rev., 108, 387-401, https://doi.org/10.1175/1520-0493(1980)108<0387: TCOCAA $>2.0 . \mathrm{CO} ; 2$. 